\title{
Regioselective Biocatalytic Hydroxylation of Fatty Acids by Cytochrome P450s
}

\author{
Lucas Hammerer $^{1,2}$. Christoph K. Winkler ${ }^{1,2}$. Wolfgang Kroutil ${ }^{2}$
}

Received: 8 November 2017 / Accepted: 3 December 2017 / Published online: 21 December 2017

(c) The Author(s) 2017. This article is an open access publication

\begin{abstract}
Cytochrome $\mathrm{P} 450$ enzymes catalyze a broad set of $\mathrm{C}-\mathrm{H}$ activation reactions, the most prominent being hydroxylation. This review provides an overview of the regioselectivity $\left(\mathrm{CH}_{3}\right.$-terminal, in-chain, and carboxylate-terminal) and the optical purity of the hydroxylation products obtained from fatty acids as far as described, focusing on systems close to preparative application.
\end{abstract}

\section{Graphical Abstract}

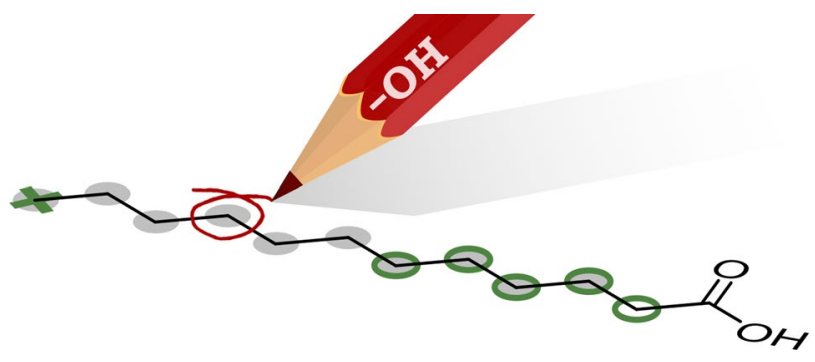

Keywords Biocatalysis $\cdot$ Enzymes $\cdot$ Hydroxylation $\cdot \mathrm{C}-\mathrm{H}$ bond activation $\cdot$ Fatty acid $\cdot$ Cytochrome P450

\section{Introduction}

Cytochrome P450 enzymes (CYPs) are iron (Fe) containing heme-proteins, which are found in most living organisms, including eukaryotes, archaea, bacteria, and viruses [1-4]. The enzymes catalyze a broad range of reactions such as hydroxylation [5], decarboxylation [6], epoxidation [7], reductive dehalogenation [8], amine/oxygen dealkylation [9], and sulfoxidation [10], employing molecular oxygen and electrons [e.g. from NAD $(\mathrm{P}) \mathrm{H}]$. Furthermore, engineered $\mathrm{P} 450$ were reported to catalyze selective

Wolfgang Kroutil

wolfgang.kroutil@uni-graz.at

1 Austrian Centre of Industrial Biotechnology, c/o University of Graz, Graz, Austria

2 Institute of Chemistry, University of Graz, NAWI Graz, BioTechMed Graz, Heinrichstrasse 28, 8010 Graz, Austria olefin-cyclopropanation via carbene transfer under oxygenfree conditions [11], enantioselective intramolecular benzylic C-H amination [12], and carbon-silicon bond formation [13], all reactions, which have not been found in nature before.

This enormous repertoire of different $\mathrm{C}-\mathrm{H}$-activation reactions renders $\mathrm{P} 450$ s highly interesting for industrial applications [14-16]. However, low turnover rates, the requirement of complex electron transfer systems and cofactor regeneration complicate the synthetic application of P450s for the production of valuable fine chemicals and consequently more efficient family members are required for bulk applications [14, 17, 18].

Fatty acids represent the natural substrates for several classes of cytochrome $\mathrm{P} 450$ s and their regioselective $\mathrm{C}-\mathrm{H}$ functionalization gives access to hydroxy-fatty acids which possess wide applications in food-, cosmetic- and pharmaceutical industry [19]. The topic underlines the unique synthetic potential of enzymes, as the fatty acid hydroxylation 
pattern of $\mathrm{P} 450$ reaches positions that are inaccessible by chemical methods. From a thermodynamic point of view particularly $\omega$-terminal hydroxylation is challenging due to its strong prim-C-H bond (approx. $100 \mathrm{kcal} \mathrm{mol}^{-1}$ ) [20]. Enzymes are known to be able to functionalize this position via an active-site architecture positioning the substrate in the required conformation for the specific reaction. Adjacent positions (in-chain, e.g. $\omega-1, \omega-2$, and $\omega$-3) show lower $\mathrm{C}-\mathrm{H}$ bond energies, however, an exclusive regioselective reaction has not been achieved [20].

Therefore, the controlled, highly (regio-) selective and straight-forward functionalization of $\mathrm{C}-\mathrm{H}$ bonds remains a dream-reaction for organic chemists and triggered the characterization of a magnitude of biocatalysts with this activity, including monooxygenases, dioxygenases, and oxidases. An emerging family of hydroxylases are the unspecific peroxygenases (UPOs, EC 1.11.2.1) that transfer one oxygen atom from a peroxide (e.g. $\mathrm{H}_{2} \mathrm{O}_{2}$ ) to the substrate. Fatty acids (C12:0 to $\mathrm{C} 20: 0)$ are hydroxylated close to the terminus and subsequent overoxidation yields subterminal ketones or dicarboxylic acids [21-23]. 12-Hydroxylases (EC 1.14.13.26) display remarkable regioselectivity as they convert oleic acid to ricinoleic acid via hydroxylation exclusively at the $\mathrm{C}-12$ position in homoallylic position to the $\mathrm{C}=\mathrm{C}$ double bond [24]. Due to a close homology to $\Delta 12$-desaturases the hydroxylation competes with desaturation [25]. Non-heme iron-dependent $\omega$-oxygenases are a large family of enzymes that catalyze the incorporation of $\mathrm{O}_{2}$ into various substrates including fatty acids [26]. The family includes lipoxygenases, as well as the AlkBGT system from Pseudomonas putida GPo1, which is famous for terminal alkane-, fatty ester-, and fatty acid-hydroxylation $[26,27]$. Lipoxygenases (EC 1.13.11) are dioxygenases that catalyze the $\mathrm{O}_{2}$-dependent hydroperoxidation of unsaturated fatty acids with a cis,cis-pentadiene motif. The hydroperoxide can be further converted to an alcohol-moiety to achieve the overall hydroxylation. Other follow-up reactions include epoxidation, $\mathrm{C}-\mathrm{C}$ bond formation, $\mathrm{C}-\mathrm{C}$ bond cleavage, ketone, and ether formation [28]. Further dioxygenases that convert fatty acids are $\alpha$-dioxygenases (EC 1.14.99.-) producing $\alpha$ - or $\beta$-hydroperoxides [29], and diol synthases (EC 1.13.11.44) that are iron-dependent multi-domain enzymes producing diols from unsaturated fatty acids [19]. Unfortunately, the mentioned catalysts suffer either from low expression levels, low productivity or low turnovers, features that are prerequisites for preparative applications.

Despite these issues, fatty acid hydroxylation with enzymes from the cytochrome $\mathrm{P} 450$ family is on a more mature level and closer to synthetic application [30], thus this review provides a comprehensive overview of fatty acid hydroxylation reactions catalyzed by cytochrome $\mathrm{P} 450$ enzymes close to preparative applications. Substrate concentrations, stereo-, and the regio-selectivity achieved by wildtype enzymes and variants are summarized and only variants with described sequences and reasonable overexpression level are considered. Other systems were described elsewhere [19, 20, 31-35]. Active site geometries and the amino acids that are responsible for the enzymes regio-selectivity are discussed in the individual chapters. A detailed review summarizing this topic has been published previously [36].

\section{Physiological Roles and Chemical Applications of Hydroxy Fatty Acids}

Hydroxy-fatty acids have wide applications, ranging from their use as additives in food industry to cosmetic industry, where they are applied as emulsifiers due to their skin moistening and anti-wrinkle properties [37]. Additionally, they are building blocks for the production of resins, waxes, biopolymers and lubricants [38]. Specific short chained $\beta$-hydroxy fatty acids such as $\beta$-hydroxy- $\beta$-methyl butyric acid, became popular as food supplements, acting as performance enhancers [39]. Hydroxy-fatty acids are commonly used in the pharmaceutical industry e.g. acting as antibiotic or anti-inflammatory [19]. A range of $(R)$ - $\alpha$-hydroxy fatty acids $\left(\mathrm{C}_{14}-\mathrm{C}_{18}\right)$ has shown antimicrobial activities against plant pathogenic organism such as Vibrio tyrogenuses [39], while $(R)-\alpha$ - and $\beta$-hydroxy fatty acids $\left(\mathrm{C}_{10}-\mathrm{C}_{12}\right.$, and $\left.\mathrm{C}_{14}\right)$ have shown antifungal activity against molds such as Aspergillus fumigatus, Penicillium commune and many more [17, 39-41]. Some $\beta$-hydroxy fatty acids (e.g. $\beta$-hydroxydodecanoic acid), are constituents of peptide antibiotics such as esperin [42], serratamolide [43], and isariin [44].

Long-chain $\alpha$-hydroxy-fatty acids are constituents of brain lipids, and of sphingolipids, which are essential components of cell membranes. Saturated $\alpha$-hydroxy-fatty acids $\left(\mathrm{C}_{20}-\mathrm{C}_{25}\right)$ are found in marine sponges as part of the phospholipids [45], while mono-unsaturated $\alpha$-hydroxy fatty acids $\left(\mathrm{C}_{22}-\mathrm{C}_{24}\right)$ are found in the phospholipids of Caribbean sea urchin [46]. In-chain hydroxylated fatty acids are surface-active compounds and are therefore found in yeast sorphorose glycolipids [47].

\section{Cytochrome P450 Classes}

The term "P450" derives from the absorption maximum of these enzymes at $450 \mathrm{~nm}$, which is observable when the iron-heme complex is in the reduced state and complexed with carbon monoxide (CO). When the thiolate ligand is protonated to form a neutral thiolate-heme ligand or in case the thiolate ligand is replaced by a histidine, resulting a nitrogen-bound form, a peak at $420 \mathrm{~nm}$ is observed [48].

Based on their sequences, the over 35,000 known P450sequences (approx. 14000 from plants) [49] are assigned to 
families ( $\geq 40 \%$ sequence homology), subfamilies ( $\geq 55 \%$ identity), and individual genes. The system is used as general nomenclature, e.g. CYP102A1 refers to the individual gene "1" from the subfamily "A" in the family "CYP102". Detailed discussions of the diversity of the cytochrome P450 family of enzymes and their classification are available in other reviews [50-52].

Furthermore, cytochrome P450s are classified according to the nature of their electron transfer system [49]. Most CYPs require additional enzymatic electron transfer partners that deliver the required electrons from a cofactor (mostly NADPH). Some P450s, such as the members of the CYP102 family or of the CYP505 family (e.g. BM3 from Bacillus megaterium, CYP102A1) are rendered self-sufficient by being fused to the reductase domain and are described as class VIII P450 enzymes [49]. Other P450s are categorized as peroxygenases due to their ability to utilize hydrogen peroxide $\left(\mathrm{H}_{2} \mathrm{O}_{2}\right)$ as both, electron- and oxygen-source [23]. Regarding (synthetic) applicability, self-sufficient CYPs or peroxygenases possess the advantage of simplifying the reaction system, as no additional enzyme for electron transfer is required. In addition to that, peroxygenases overcome the problem of uncoupling due to their mechanism.

For the sake of this review, fatty acid-hydroxylating CYPs are considered and classified as carboxy-terminal- ( $\alpha$ - to $\beta$ ), in-chain- $(\omega-1, \omega-2, \omega-3, \cdots, \gamma)$ and terminal-hydroxylating enzymes $(\omega)[34,35]$.

Eukaryotic CYP families with fatty acid hydroxylation activities are: CYP1, CYP2, CYP4, CYP52, CYP76, CYP77, CYP78, CYP81, CYP86, CYP92, CYP94, CYP96, CYP505, CYP703, and CYP709, while CYP102, CYP107, CYP119, CYP152, CYP153, and CYP267 summarize the prokaryotic families showing fatty acid hydroxylation activities.

\section{Mechanistic Considerations}

The iron-containing heme in the active sites of cytochrome $\mathrm{P} 450 \mathrm{~s}$ is responsible for the enzymes characteristic red color. The iron(IV)-oxidoporphyrin radical $\mathrm{Fe}^{4+}=\mathrm{O}$, also described as compound I (Fig. 1) is the active species enabling various reactions [53].

The mechanism (Fig. 1) starts with the displacement of a molecule of water bound to the low-spin heme- $\mathrm{Fe}^{3+}$ (ferric) resting-state of the enzyme. This triggers a spin-change in the complexed $\mathrm{Fe}^{3+}$ into the ferric "high-spin" state which results in a rearrangement of the complex geometry inducing a strong reorganization of the overall enzyme. A subsequent single electron transfer yields the ferrous $\left(\mathrm{Fe}^{2+}\right)$ state which is transferred into the ferric state by coordinating molecular oxygen $\left(\mathrm{O}_{2}\right)$ as superoxido radical $\left(\mathrm{O}_{2}^{--}\right)$. This is then reduced to a ferric peroxido anion by a second single electron transfer. After protonation, the so-called "compound 0" is formed which releases $\mathrm{H}_{2} \mathrm{O}$ after further protonation via heterolytic cleavage of the $\mathrm{O}-\mathrm{O}$ bond. The resulting reactive oxidative species "compound I" (ferryl oxido: $\mathrm{Fe}^{4+}=\mathrm{O}$, one electron delocalized in the porphyrin) enables a variety of radical oxidation reactions, including hydroxylation $[54,55]$. Since not accessible to characterization with spectroscopic methods, the last steps of the catalytic cycle are debated. However, the most broadly accepted mechanism starts with the abstraction of a hydrogen-radical from the substrate forming "compound II" $\left(\mathrm{Fe}^{4+}-\mathrm{OH}\right)$ and is closed by the "rebound" of a hydroxy-radical and the substrate radical, forming the alcohol product, which is displaced by a water molecule leading to the resting state [55].

In this catalytic cycle, redox equivalents might be lost via undesired bypasses as the iron heme complex might undergo uncoupling reactions [56]. Uncoupling can occur through three pathways: (i) via autoxidation of the ferric superoxo radical accompanied with superoxide radical anion formation (autoxidation shunt), (ii) by losing $\mathrm{H}_{2} \mathrm{O}_{2}$ from compound 0 (peroxide shunt) and (iii) deoxygenation of compound I, producing $\mathrm{H}_{2} \mathrm{O}$ (oxidase shunt). All uncoupling reactions release the enzyme in the high spin state and thereby destroy reduction equivalents [54]. For a handful of $\mathrm{P} 450$ that can utilize $\mathrm{H}_{2} \mathrm{O}_{2}$ in a peroxygenase reactionmode, the mechanism is short-cut by a reversal of the peroxide shunt. Essentially, this eliminates one of the options for uncoupling (Fig. 1). A significant advantage of P450 peroxygenases using $\mathrm{H}_{2} \mathrm{O}_{2}$ is the avoidance of $\mathrm{NAD}(\mathrm{P}) \mathrm{H}$ and the possible need for additional enzymes [57]. However, $\mathrm{P} 450$ peroxygenases are also prone to inactivation due to the required high concentrations of hydrogen peroxide [58-60]. Mutagenesis approaches including directed evolution [61] and site-directed mutagenesis [59] showed successful stabilization and increased activity of peroxygenases.

\section{Carboxy-Terminal Hydroxylation}

P450 enzymes hydroxylating fatty acids at methylene carbons close to the carboxylic terminus (e.g. $\alpha$ - and $\beta$-position) belong to peroxygenases from the CYP152 family. CYP152 members utilize fatty acids as natural substrates. Binding of the carboxyl moiety to a conserved arginine (close to position 241/242) is necessary for reaction [57]. $\mathrm{P} 450_{\mathrm{SP} \alpha}(\mathrm{SP} \alpha, \mathrm{CYP} 152 \mathrm{~B} 1)$ is the first $\mathrm{P} 450$ peroxygenase, which was isolated from the anaerobe organism Sphingomonas paucimobilis [62]. The highly selective enzyme hydroxylates fatty acids exclusively in $\alpha$-position in a $(S)$-selective manner. Similarly, the orthologue P450 $\mathrm{CLA}$ (CLA, CYP152A2) from Clostridium acetobutylicum hydroxylates fatty acids mainly at the $\alpha$-position, however with poorer selectivity as $\operatorname{SP} \alpha$, as both, $\alpha$ - and the $\beta$-hydroxy-acid is observed [63]. $\mathrm{P} 450_{\mathrm{Bs} \beta}$ 


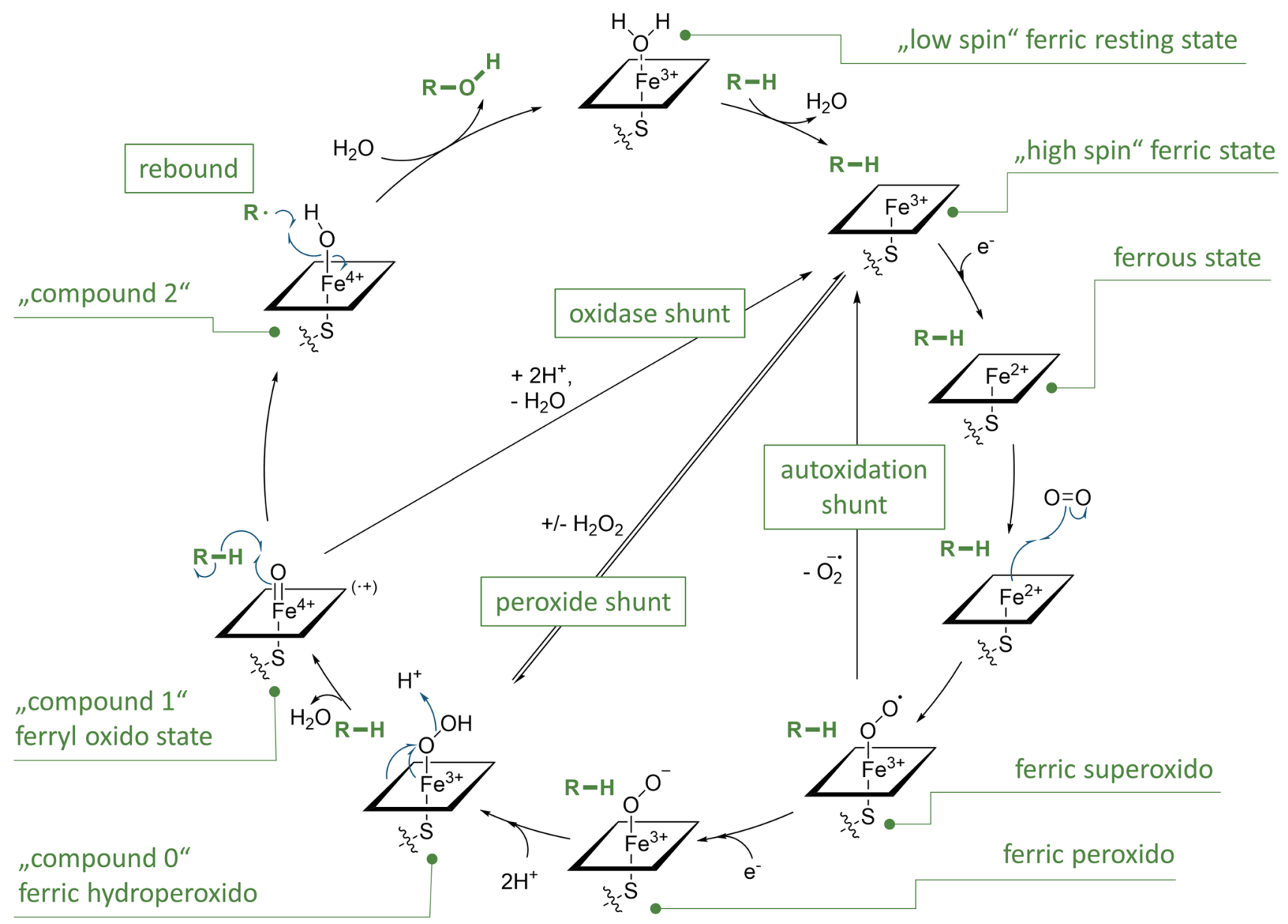

Fig. 1 Mechanism of the cytochrome P450 catalyzed hydroxylation including shunt pathways

(BS $\beta$, CYP152A1) from Bacillus subtilis which shows $42 \%$ sequence identity with $\mathrm{SP} \alpha$ has hydroxylation activity on fatty acids in $\alpha$ - and $\beta$-position with a preference for the $\beta$-position. Furthermore was demonstrated, that hydroxylation pattern depends on both, substrate, and redox-partner [64]. The CYP152 family member $\mathrm{P} 450 \mathrm{OleT}_{\mathrm{JE}}$ from Jeotgalicoccus species (CYP152L1) possessing $41 \%$ sequence identity with $\mathrm{P} 450_{\mathrm{Bs} \beta}$ performs actually mainly oxidative fatty acid decarboxylation yielding terminal alkenes. However, the family's $\alpha$-, and $\beta$-hydroxylation activity was also observed [6]. The first enzyme, reported to hydroxylate fatty acids (C12:0-C18:0) at each position from $\alpha$ to $\varepsilon$ is P450 $0_{\mathrm{MP}}$ (MP) from Methylobacterium populi [65]. Similar to $\mathrm{OleT}_{\mathrm{JE}}$, oxidative decarboxylation was observed in addition to hydroxylation on C16:0 and C18:0.

\section{1 $\mathrm{P} 450_{\mathrm{SPa}}$ (CYP152B1 from Sphingomonas paucimobilis)}

The $\alpha$-hydroxylase from Sphingomonas paucimbobilis $(\mathrm{SP} \alpha)$ was the first P450 enzyme discovered, which is able to utilize $\mathrm{H}_{2} \mathrm{O}_{2}$ instead of molecular $\mathrm{O}_{2}$ and $\mathrm{NAD}(\mathrm{P})$ $\mathrm{H}$ to hydroxylate fatty acids [66]. It can be expressed in soluble form in E. coli using a GST-tag [62, 67]. The crystal structure was solved in 2011 with palmitic acid cocrystalized as substrate with a resolution of $1.65 \AA$ (PDB code: 3 AWM) [68]. SP $\alpha$ accepts $\mathrm{C} 11: 0$ to $\mathrm{C} 18: 0$ as substrates (Table 1, entries 2-9; Fig. 2). Recently, a cascade was reported, that allowed the conversion of fatty acids to $\alpha$-ketoacids in a one pot fashion by combining SP $\alpha$ and $\alpha$-hydroxyacid oxidase via an internal $\mathrm{H}_{2} \mathrm{O}_{2}$ recycling . Here C6:0, C7:0, C8:0 and C10:0 were demonstrated to be substrates for $\mathrm{SP} \alpha[69]$.

Myristic acid (C14:0) was postulated to be the natural substrate of SP $\alpha$ and is hydroxylated stereo-, and regioselectively to produce $(S)$-2-hydroxymyristic acid (94\% e.e.; Table 1, entry 5). The product is the major hydroxy fatty acid found in the sphingolipids of the native organism Sphingomonas paucimobilis. Additionally, 16-hydroxy-palmitic acid (entry 11), arachidonic acid (C20:4, entry 10) and monomethyl hexadecanedioic acid (entry 12) are hydroxylated in $\alpha$-position. 
Table $1 \alpha$-Hydroxylation of fatty acids catalyzed by $\mathrm{P}^{250} 0_{\mathrm{SP} \alpha}(\mathrm{CYP} 152 \mathrm{~B} 1$ from Sphingomonas paucimobilis) and its variants

\begin{tabular}{|c|c|c|c|c|c|c|c|}
\hline Entry & Variant & Redox system & Substrate & Conc. (mM) & TON $\left(\min ^{-1}\right)$ & e.e. $(\%)$ & Refs. \\
\hline 1 & Wildtype & $\mathrm{H}_{2} \mathrm{O}_{2}$ & Phytanic acid & 0.1 & n.a & n.r. & {$[62]$} \\
\hline 2 & Wildtype & $\mathrm{H}_{2} \mathrm{O}_{2}$ & C11:0 & $\leq 0.12$ & 490 & n.r. & [70] \\
\hline 3 & Wildtype & $\mathrm{H}_{2} \mathrm{O}_{2}$ & $\mathrm{C} 12: 0$ & $\leq 0.12$ & 3000 & n.r. & [70] \\
\hline 4 & Wildtype & $\mathrm{H}_{2} \mathrm{O}_{2}$ & C13:0 & $\leq 0.12$ & 3600 & n.r. & {$[70]$} \\
\hline 5 & Wildtype & $\mathrm{H}_{2} \mathrm{O}_{2}$ & C14:0 & $\leq 0.12$ & 3800 & $94(S)$ & {$[53,68,70]$} \\
\hline 6 & Wildtype & $\mathrm{H}_{2} \mathrm{O}_{2}$ & $\mathrm{C} 15: 0$ & $\leq 0.12$ & 3400 & n.r. & [70] \\
\hline 7 & Wildtype & $\mathrm{H}_{2} \mathrm{O}_{2}$ & C16:0 & $\leq 0.12$ & 4700 & n.r. & {$[70]$} \\
\hline 8 & Wildtype & $\mathrm{H}_{2} \mathrm{O}_{2}$ & C17:0 & $\leq 0.12$ & 4000 & n.r. & [70] \\
\hline 9 & Wildtype & $\mathrm{H}_{2} \mathrm{O}_{2}$ & C18:0 & $\leq 0.12$ & 2500 & n.r. & [70] \\
\hline 10 & Wildtype & $\mathrm{H}_{2} \mathrm{O}_{2}$ & Arachidonic acid 20:4 & $\leq 0.12$ & 4400 & n.r. & {$[70]$} \\
\hline 11 & Wildtype & $\mathrm{H}_{2} \mathrm{O}_{2}$ & 16-OH C16:0 & $\leq 0.12$ & 630 & n.r. & {$[70]$} \\
\hline 12 & Wildtype & $\mathrm{H}_{2} \mathrm{O}_{2}$ & Monomethyl hexadecanedionate & $\leq 0.12$ & 550 & n.r. & {$[70]$} \\
\hline 13 & L78F & $\mathrm{H}_{2} \mathrm{O}_{2}$ & C14:0 & $\leq 0.12$ & 5500 & $92(S)$ & {$[68]$} \\
\hline 14 & F288G & $\mathrm{H}_{2} \mathrm{O}_{2}$ & $\mathrm{C} 14: 0$ & $\leq 0.06$ & 770 & $62(S)$ & {$[68]$} \\
\hline 15 & $\mathrm{~L} 78 \mathrm{~F} / \mathrm{F} 288 \mathrm{G}$ & $\mathrm{H}_{2} \mathrm{O}_{2}$ & $\mathrm{C} 14: 0$ & $\leq 0.12$ & 1300 & $58(S)$ & {$[68]$} \\
\hline 16 & $\mathrm{~A} 172 \mathrm{~F}$ & $\mathrm{H}_{2} \mathrm{O}_{2}$ & $\mathrm{C} 14: 0$ & $\leq 0.12$ & 1200 & $94(S)$ & {$[68]$} \\
\hline 17 & $\mathrm{~A} 172 \mathrm{~F} / \mathrm{F} 288 \mathrm{G}$ & $\mathrm{H}_{2} \mathrm{O}_{2}$ & $\mathrm{C} 14: 0$ & $\leq 0.06$ & 100 & $66(S)$ & {$[68]$} \\
\hline
\end{tabular}

In case different values were reported in different studies, the higher number is given

Conc. substrate concentration, e.e. enantiomeric excess of the product, TON turnover number, n.r. not reported in the reference

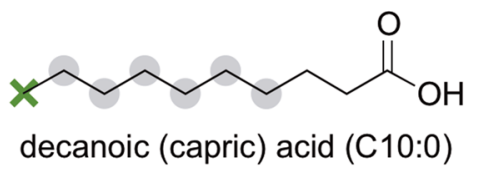<smiles>CCCCCCCCCOC(=O)O</smiles><smiles>[X]CCCCCOOOOC(=O)O</smiles><smiles>CC=CCCCCCCCCOC(=O)O</smiles><smiles>[X]CCCCCCCCOOOOC(=O)O</smiles>

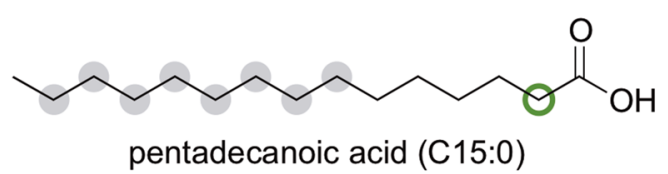<smiles>[X]CCC=CCCCCCCCCOOC(=O)O</smiles><smiles>CC=CCCCCCCCCCCCOC(=O)O</smiles><smiles>CC=CCCCCCCCCCCOOC(=O)O</smiles>

Fig. 2 Positions in saturated fatty acids, that have been reported to be functionalized with cytochrome P450s by (i) carboxy-terminal hydroxylation (indicated with green rings, for details see Tables 1, 2,
3, 4), (ii) in-chain hydroxylation (indicated with grey filled circles, for details see Table 5), and (iii) terminal hydroxylation (indicated with a "x", for details see Table 8) 
1,16-Hexadecanedioic acid is converted with lower turnover rates than the corresponding monoester, which led to the assumption that the negative charge of the dicarboxylic acid might interfere with residues in the active site [70]. Branched chained fatty acids, such as phytanic acid (a degradation product of chlorophyll) are also converted (Table 1, entry 1) [62], whereas long-chain alkanes, fatty alcohols, and fatty aldehydes are non-substrates. Therefore, the carboxylic acid moiety is crucial for substrate binding and activity.

The high selectivity of SP $\alpha$ was tried to be explained by blockage of the $\beta$-position by a phenylalanine at position 288 (F288) [53], although mutations of F288 to glycine (F288G) did not result in any change in regioselectivity (Table 1, entry 14) [68]. In another paper, it is described that F288 hinders the substrate to undergo conformational changes thereby stabilizing the substrate's $\alpha$-carbon on top of the reactive heme. The conserved arginine at position 241 (R241) serves as the carboxylate-anchor to bind fatty acid substrates, an interaction crucial for stabilization of compound 0. Proline in position 242 (P242) stabilizes the substrate's pro-S C-H above the heme, thereby influencing the enantioselectivity of the enzyme. This is confirmed by a P242A mutation (MD simulation), which stabilizes the pro$R \mathrm{C}-\mathrm{H}$ on top of the reactive heme species [53].

In order to pinpoint the reason for their different regioselectivities, several residues of SP $\alpha$ were exchanged for the homologous amino acids from $\mathrm{Bs} \beta$ (that is active on both, positions $\alpha$, and $\beta$ ). Nevertheless, variants L78F, F288G, and $\mathrm{A} 172 \mathrm{~F} / \mathrm{F} 288 \mathrm{G}$ remained exclusively regioselective for the $\alpha$-position, but their stereoselectivity decreased (Table 1 , entries 13-17) [68].

Interestingly, SP $\alpha$ was reported to epoxidize styrenes in the presence of $(R)$-ibuprofen, acting as decoy molecule. The crystal structure of the ibuprofen bound to SP $\alpha$ revealed that its carboxyl moiety initiated the epoxidation as acid basecatalyst (resolution 1.9 $\mathrm{A}$, PDB code: 3VM4) [68].
Furthermore, calculations demonstrated, that in the case of $\mathrm{P} 450$ peroxygenase $\mathrm{SP} \alpha$, the mechanism differs from traditional $\mathrm{P} 450 \mathrm{~s}$, as the substrate stabilizes compound 0 and the $\mathrm{O}-\mathrm{O}$ bond is homolytically cleaved, producing a hydroxy-radical which then abstracts a hydrogen radical from the iron-complex, thereby forming compound I [53].

\section{2 $\mathrm{P} 450_{\mathrm{CLA}}$ (CYP152A2 from Clostridium acetobutylicum)}

P450 CLA (CLA) catalyzes fatty acid hydroxylation on the $\alpha$-, and $\beta$-position of saturated and unsaturated fatty acids with chain lengths from $\mathrm{C} 12: 0$ to $\mathrm{C} 16: 0$ (Table 2; Fig. 2), mainly at the $\alpha$-position. Shorter fatty acids (C6:0, C7:0 and $\mathrm{C} 10: 0)$ are hydroxylated in $\alpha$-position as demonstrated in a one pot cascade combining CLA and $\alpha$-hydroxyacid oxidase to produce $\alpha$-ketoacids [69]. Although substrate binding was demonstrated via a spin-shift, methyl esters were reported to be non-substrates [63]. The enzyme accepts both, $\mathrm{H}_{2} \mathrm{O}_{2}$, and $\mathrm{O}_{2}$ (in the presence of electron transfer partner and cofactors) as redox-system [63]. Interestingly, after a reaction time of $60 \mathrm{~min}$, CLA converted 10 times more substrate with the flavodoxin (Fld)/ flavodoxin reductase (Fpr) system from $E$. coli than with $\mathrm{H}_{2} \mathrm{O}_{2}$ as the oxidant (Table 2, entries 1-2). With redox system of CYP102A, this value increased even further (30-40; Table 2, entry 3). In contrast to this, the initial rates (measured after $2 \mathrm{~min}$ ) were highest for $\mathrm{H}_{2} \mathrm{O}_{2}$. Furthermore, the electron transfer partner influenced the activity as well as the hydroxylation pattern. Interestingly, in contrast to the system employing $\mathrm{H}_{2} \mathrm{O}_{2}$ both systems (CYP102A1 reductase and Fld/Fpr) gave $\beta$-hydroxylated C12:0 (Table 2, entries 1-3) [63]. The crystal structure of CLA remains to be solved and no mutagenesis studies are published so far.
Table 2 P450 $\mathrm{CLA}$-mediated hydroxylation of fatty acids (CYP152A2 from Clostridium acetobutylicum)

\begin{tabular}{|c|c|c|c|c|c|c|c|}
\hline \multirow[t]{2}{*}{ Entry } & \multirow[t]{2}{*}{ Redox system } & \multirow[t]{2}{*}{ Substrate } & \multirow[t]{2}{*}{ Conc. (mM) } & \multirow[t]{2}{*}{ Con. (\%) } & \multicolumn{2}{|c|}{$\begin{array}{l}\text { Distribution of } \\
\text { products [\%] }\end{array}$} & \multirow[t]{2}{*}{ Refs. } \\
\hline & & & & & $\alpha$ & $\beta$ & \\
\hline 1 & $\mathrm{H}_{2} \mathrm{O}_{2}$ & $\mathrm{C} 12: 0$ & 0.025 & 8 & $>99$ & $<1$ & {$[63]$} \\
\hline 2 & Fld and Fpr from E. coli & $\mathrm{C} 12: 0$ & 0.250 & 10 & 69 & 31 & {$[63]$} \\
\hline 3 & CYP102A1 reductase & $\mathrm{C} 12: 0$ & 0.250 & 42 & 83 & 17 & {$[63]$} \\
\hline 4 & $\mathrm{H}_{2} \mathrm{O}_{2}$ & $\mathrm{C} 14: 0$ & 0.025 & 34 & 66 & 34 & [63] \\
\hline 5 & Fld and Fpr from E. coli & $\mathrm{C} 14: 0$ & 0.250 & 17 & 66 & 34 & {$[63]$} \\
\hline 6 & CYP102A1 reductase & $\mathrm{C} 14: 0$ & 0.250 & 61 & 84 & 16 & {$[63]$} \\
\hline 7 & $\mathrm{H}_{2} \mathrm{O}_{2}$ & $\mathrm{C} 16: 0$ & 0.025 & 10 & 48 & 52 & {$[63]$} \\
\hline 8 & Fld and Fpr from E. coli & $\mathrm{C} 16: 0$ & 0.250 & 11 & 88 & 12 & {$[63]$} \\
\hline 9 & CYP102A1 reductase & $\mathrm{C} 16: 0$ & 0.250 & 30 & 87 & 13 & {$[63]$} \\
\hline
\end{tabular}

Conc. substrate concentration, Con. conversion 


\section{3 $\mathrm{P} 450_{\mathrm{BS} \beta}$ (CYP152A1 from Bacillus subtilis)}

$\mathrm{P} 450_{\mathrm{BS} \beta}(\mathrm{BS} \beta)$ was described to be a peroxygenase, that catalyzes fatty acid hydroxylation in $\alpha$ - and $\beta$-position [87]. When tested with $\mathrm{C} 14: 0$ as substrate and $\mathrm{H}_{2} \mathrm{O}_{2}$ as the oxidant, $\mathrm{BS} \beta$ led to $\alpha / \beta$ hydroxylation at a ratio of roughly $40 / 60$, producing the $(R)$-enantiomer in excess for both positions (Table 3, entry 1; Fig. 2). However, while the $\beta$-position is hydroxylated with high stereoselectivity (96\% e.e.), the hydroxylation in $\alpha$-position is less selective, displaying an e.e. of $52 \%(R)$ [87]. In addition to its activity on fatty acids, BS $\beta$ was reported to hydroxylate polycyclic aromatic hydrocarbons (PAHs) such as anthracene, 9-methylanthracene, and azulene [88]. Epoxidation of styrene and hydroxylation of ethylbenzene was enabled by tricking the enzyme with short-chain fatty acids as decoy molecules [89]. The involvement of the decoy molecule was confirmed by crystallizing the enzyme with heptanoic acid (C7:0) bound to the conserved arginine in the active site (R242) [90]. In addition,

Table $3 \mathrm{P} 450_{\mathrm{BS} \beta}$-mediated hydroxylation of fatty acids (CYP152A1 from Bacillus subtilis)

\begin{tabular}{|c|c|c|c|c|c|c|c|c|c|}
\hline \multirow[t]{2}{*}{ Entry } & \multirow[t]{2}{*}{ Variant } & \multirow[t]{2}{*}{ Redox system } & \multirow[t]{2}{*}{ Substrate } & \multirow[t]{2}{*}{ Conc. (mM) } & \multirow[t]{2}{*}{$\begin{array}{l}\text { TON }\left(\min ^{-1}\right) \\
{[\text { Con. }(\%)]}\end{array}$} & \multirow[t]{2}{*}{ Alkene (\%) } & \multicolumn{2}{|c|}{$\begin{array}{l}\text { Distribution of products } \\
(\%) \text { [e.e. }(\%)]\end{array}$} & \multirow[t]{2}{*}{ Refs. } \\
\hline & & & & & & & $\alpha$ & $\beta$ & \\
\hline 1 & Wildtype & $\mathrm{H}_{2} \mathrm{O}_{2}$ & $\mathrm{C} 14: 0$ & $\leq 0.12$ & 1400 & n.r. & $43(52 R)$ & $57(96 R)$ & {$[68]$} \\
\hline 2 & Wildtype & $\mathrm{H}_{2} \mathrm{O}_{2}$ & $\mathrm{C} 14: 0$ & 0.2 & 159 & n.r. & 38 & 62 & {$[64]$} \\
\hline 3 & L237K & $\mathrm{H}_{2} \mathrm{O}_{2}$ & $\mathrm{C} 14: 0$ & 0.2 & 154 & n.r. & 40 & 60 & [64] \\
\hline 4 & L241K & $\mathrm{H}_{2} \mathrm{O}_{2}$ & $\mathrm{C} 14: 0$ & 0.2 & 156 & n.r. & 31 & 69 & {$[64]$} \\
\hline 5 & $\mathrm{R} 242 \mathrm{~K}$ & $\mathrm{H}_{2} \mathrm{O}_{2}$ & $\mathrm{C} 14: 0$ & 0.2 & 6 & n.r. & 48 & 52 & [64] \\
\hline 6 & P243K & $\mathrm{H}_{2} \mathrm{O}_{2}$ & $\mathrm{C} 14: 0$ & 0.2 & n.r. & n.r. & n.r. & n.r. & {$[64]$} \\
\hline 7 & P243H & $\mathrm{H}_{2} \mathrm{O}_{2}$ & $\mathrm{C} 14: 0$ & 0.2 & n.r. & n.r. & n.r. & n.r. & [64] \\
\hline 8 & P243A & $\mathrm{H}_{2} \mathrm{O}_{2}$ & $\mathrm{C} 14: 0$ & 0.2 & 34 & n.r. & 48 & 52 & [64] \\
\hline 9 & P243S & $\mathrm{H}_{2} \mathrm{O}_{2}$ & $\mathrm{C} 14: 0$ & 0.2 & 12 & n.r. & 53 & 47 & [64] \\
\hline 10 & I244K & $\mathrm{H}_{2} \mathrm{O}_{2}$ & C14:0 & 0.2 & 88 & n.r. & 48 & 52 & [64] \\
\hline 11 & V245K & $\mathrm{H}_{2} \mathrm{O}_{2}$ & $\mathrm{C} 14: 0$ & 0.2 & 85 & n.r. & 18 & 82 & [64] \\
\hline 12 & A246K & $\mathrm{H}_{2} \mathrm{O}_{2}$ & $\mathrm{C} 14: 0$ & 0.2 & n.r. & n.r. & n.r. & n.r. & [64] \\
\hline 13 & I247K & $\mathrm{H}_{2} \mathrm{O}_{2}$ & $\mathrm{C} 14: 0$ & 0.2 & 35 & n.r. & 21 & 79 & [64] \\
\hline 14 & S248K & $\mathrm{H}_{2} \mathrm{O}_{2}$ & $\mathrm{C} 14: 0$ & 0.2 & 34 & n.r. & 40 & 60 & [64] \\
\hline 15 & Y249K & $\mathrm{H}_{2} \mathrm{O}_{2}$ & $\mathrm{C} 14: 0$ & 0.2 & 108 & n.r. & 53 & 47 & [64] \\
\hline 16 & $\mathrm{~F} 250 \mathrm{~K}$ & $\mathrm{H}_{2} \mathrm{O}_{2}$ & $\mathrm{C} 14: 0$ & 0.2 & 90 & n.r. & 21 & 79 & {$[64]$} \\
\hline 17 & L251K & $\mathrm{H}_{2} \mathrm{O}_{2}$ & C14:0 & 0.2 & 158 & n.r. & 36 & 64 & {$[64]$} \\
\hline 18 & F79L & $\mathrm{H}_{2} \mathrm{O}_{2}$ & $\mathrm{C} 14: 0$ & $\leq 0.12$ & 1400 & n.r. & $75(24 R)$ & $25(98 R)$ & [68] \\
\hline 19 & V170F & $\mathrm{H}_{2} \mathrm{O}_{2}$ & $\mathrm{C} 14: 0$ & 0.2 & 113 & n.r. & 38 & 62 & [71] \\
\hline 20 & F79L/V170L & $\mathrm{H}_{2} \mathrm{O}_{2}$ & $\mathrm{C} 14: 0$ & 0.2 & 35 & n.r. & 60 & 40 & [71] \\
\hline 21 & G290F & $\mathrm{H}_{2} \mathrm{O}_{2}$ & $\mathrm{C} 14: 0$ & $\leq 0.12$ & 1900 & n.r. & $95(42 S)$ & $5(70 R)$ & [68] \\
\hline 22 & F79L/G290F & $\mathrm{H}_{2} \mathrm{O}_{2}$ & $\mathrm{C} 14: 0$ & $\leq 0.12$ & 890 & n.r. & $77(44 S)$ & $23(72 R)$ & [68] \\
\hline 23 & Wildtype $^{\mathrm{a}}$ & $\mathrm{H}_{2} \mathrm{O}_{2}$ & C16:0 & 0.2 & n.r. & 17 & 38 & 45 & [72] \\
\hline 24 & $\mathrm{Q} 85 \mathrm{H}^{\mathrm{a}}$ & $\mathrm{H}_{2} \mathrm{O}_{2}$ & C16:0 & 0.2 & n.r. & 23 & 16 & 61 & [72] \\
\hline 25 & Wildtype & $\mathrm{H}_{2} \mathrm{O}_{2}$ & $\mathrm{C} 12: 0$ & 0.025 & (86) & n.r. & 14 & 86 & {$[63]$} \\
\hline 26 & Wildtype & Fld and Fpr from E. coli & $\mathrm{C} 12: 0$ & 0.250 & (93) & n.r. & 34 & 66 & {$[63]$} \\
\hline 27 & Wildtype & CYP102A1 reductase & $\mathrm{C} 12: 0$ & 0.250 & (97) & n.r. & 35 & 65 & {$[63]$} \\
\hline 28 & Wildtype & $\mathrm{H}_{2} \mathrm{O}_{2}$ & $\mathrm{C} 14: 0$ & 0.025 & (98) & n.r. & 7 & 93 & {$[63]$} \\
\hline 29 & Wildtype & Fld and Fpr from E. coli & $\mathrm{C} 14: 0$ & 0.250 & (94) & n.r. & 15 & 85 & {$[63]$} \\
\hline 30 & Wildtype & CYP102A1 reductase & $\mathrm{C} 14: 0$ & 0.250 & (97) & n.r. & 18 & 82 & {$[63]$} \\
\hline 31 & Wildtype & $\mathrm{H}_{2} \mathrm{O}_{2}$ & C16:0 & 0.025 & (64) & n.r. & 10 & 90 & {$[63]$} \\
\hline 32 & Wildtype & Fld and Fpr from E. coli & $\mathrm{C} 16: 0$ & 0.250 & $(75)$ & n.r. & 20 & 80 & [63] \\
\hline 33 & Wildtype & CYP102A1 reductase & C16:0 & 0.250 & (78) & n.r. & 21 & 79 & [63] \\
\hline
\end{tabular}

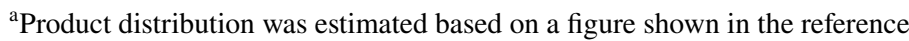

Conc. substrate concentration, TON turnover number, Con. conversion given in round brackets, e.e. enantiomeric excess of the product given in round brackets, $n . r$. not reported in the reference 
3,5,3',5'-tetramethylbenzidine (TMB) is oxidized by BS $\beta$ in a myristic acid (C14:0) dependent reaction [91].

Site-directed mutagenesis was performed to investigate the mechanistic role of residues in the distal helix of the heme. R242A shows fivefold decreased substrate binding affinity compared to the wildtype, associated with a loss of activity. The variants $\mathrm{P} 243 \mathrm{~K}$ and A246K gave similar results. Therefore, R242, P243, and A246 were hypothesized to be crucial for substrate orientation and activity. Furthermore, most variants resulted in a variation of the $\alpha / \beta$-hydroxylation ratio at cost of activity (Table 3, entries 2-17) [64]. In 2003, as the first example of its family, the crystal structure of BS $\beta$ was solved with C16:0 bound as substrate at a resolution of $2.1 \AA$ (PDB code: 1IZO) [92]. The structure revealed that BS $\beta$ lacks $\mathrm{acid} / \mathrm{base}$ residues in the distal site of the heme, which are usually conserved in peroxygenases and peroxidases [57]. Furthermore, binding of a carboxylate to the R242 was shown to be crucial for compound I formation. The stabilization of the aliphatic side chain of the substrate by a hydrophobic substrate channel was demonstrated [71]. To determine the importance of residues involved in the hydrophobic substrate channel, the F79L, V170F, and F79L/V170F variants were tested for hydroxylation of C14:0 (entries 18-20). The F79L mutation reduced the specific activity by $50 \%$ and the $\alpha / \beta$-hydroxylation ratio was shifted towards the $\alpha$-position. The mutation V170F retained $30 \%$ of the wildtype activity and showed a minimal shift of the hydroxylation ratio in preference of the $\beta$-position, while the double mutant (F79L/V170F) gave just $10 \%$ of wildtype activity with a slight preference of $\alpha$-hydroxylation [71]. Based on the alignment to $\mathrm{SP} \alpha$, the BS $\beta$ variants F79L, G290F, and F79L/G290F were prepared in order to evaluate their effect on regio-, and stereo-selectivity on C14:0 (entries 21-22). G290F increased activity giving 95\% hydroxylation in $\alpha$-position and led to a switch of stereo-preference compared to the wildtype giving the $(S)$-enantiomer (e.e. $42 \%$, entry 21 ), while in $\beta$-position still the $(R)$-alcohol was formed.

$\mathrm{BS} \beta$ was shown to accept electrons not just from $\mathrm{H}_{2} \mathrm{O}_{2}$ but additionally from electron transfer proteins such as the BM3 reductase domain (CYP102A1) and Fld and Fpr from E. coli, respectively, using NADPH as the cofactor in the presence of $\mathrm{O}_{2}$. The hydroxylation ratio was influenced by the nature of the redox system (entries 25-33) [63].

Oxidative fatty acid decarboxylation activity of BS $\beta$ wildtype in addition to its hydroxylation activity was reported only in one case [72]. A Q85H variant accelerated the overall activity by 1.5 -fold compared to the wildtype, showed enhanced decarboxylation-activity and shifted the hydroxylation ratio in favor of the $\beta$-position (entries 23 and 24).

\section{4 $\mathrm{P} 450_{\text {OleT }}$ (CYP152L1 from Jeotgalicoccus species) OleT $_{\text {JE }}$}

In 2011, the first enzymatic oxidative decarboxylation producing terminal olefins was reported to be catalyzed by $\mathrm{P} 450_{\text {Olet }}\left(\mathrm{OleT}_{\mathrm{JE}}\right)$ from Jeotgalicoccus species [72]. Ole $\mathrm{T}_{\mathrm{JE}}$ still is the only enzyme from the CYP152 family described so far, that prefers oxidative decarboxylation over hydroxylation of fatty acids. Ole $_{\mathrm{IE}}$ is able to utilize dicarboxylic acids $\left(\mathrm{C}_{7}-\mathrm{C}_{18}\right)$ and $\omega$-alkenoic acids $\left(\mathrm{C}_{6}-\mathrm{C}_{11}\right)$ to produce terminal dienes [93]. Nevertheless, hydroxylation was still detected to a low extent, preferably in $\beta$ - rather than in $\alpha$-position. As all CYP152 members, OleT $\mathrm{JE}_{\mathrm{JE}}$ is described to utilize $\mathrm{H}_{2} \mathrm{O}_{2}$ as the main electron source, however, with low activity. Replacing $\mathrm{H}_{2} \mathrm{O}_{2}$ with the bacterial electron transfer system CamAB extended the substrate scope towards shorter fatty acids (C4:0-C22:0, $10 \mathrm{mM}$ substrate) [6]. A fusion protein with the electron transfer system from Rhodococcus species (RhFRED) was less active than the original process utilizing $\mathrm{H}_{2} \mathrm{O}_{2}$ (except for C12:0) and fatty acids shorter than ten carbon atoms were not converted [94].

The crystal structure of $\mathrm{OleT}_{\mathrm{JE}}$ was solved in 2014 at a resolution of $2.5 \AA$ with arachidic acid (eicosanoic acid, C20:0) bound as substrate (PDB code: 4L40). Additionally, the crystal structure of the substrate-free form was reported (2.3 Å, PDB code: 4L54). Similar as for other CYP152 family members the carboxylate is bound by the conserved arginine (R245) [95]. The R245 $\mathrm{L} \mathrm{OleT}_{\mathrm{JE}}$ variant showed a preference for $\alpha$-hydroxylation with C10:0, C12:0, and C14:0, while decarboxylation was drastically diminished. For C16:0, decarboxylation was detected, however in similar extent as hydroxylation in $\alpha$ - and $\beta$-position. Interestingly the R245L variant gave exclusively alkene product when C18:0 was tested as substrate. The F79A variant of OleT $_{\mathrm{JE}}$ mostly decreased the alkene/hydroxy acid product ratio [96].

The reaction mechanism for the oxidative decarboxylation is under debate $[96,97]$. After compound I formation by $\mathrm{H}_{2} \mathrm{O}_{2}$ via the peroxide shunt, a hydrogen atom is abstracted from the $\alpha$ - or $\beta$ - position, producing the corresponding carbon radical. Now either the classical oxygen rebound occurs towards substrate hydroxylation or the reaction proceeds towards decarboxylation. Therefore, either an additional electron can be abstracted from the $\beta$-position resulting in a carbocation, triggering decarboxylation, or the second electron is abstracted from the carboxylate and the product is formed via a substrate diradical.

\section{5 $\mathrm{P}^{250}$ MP (CYP152MP from Methylobacterium populi)}

$\mathrm{P} 450_{\mathrm{MP}}$ (MP), a peroxygenase from the CYP152 family, can be expressed in soluble form in E. coli by fusing it to a GST-Tag. This enzyme can convert C16:0 and C18:0 to 
1-alkenes via an oxidative decarboxylation as well as to $\alpha-, \beta-, \gamma-, \delta$ - or $\varepsilon$-hydroxy fatty acids (Table 4 , entries $1-4$; Fig. 2). For medium chained fatty acids such as C12:0 and C14:0 no decarboxylation was observed in favor of $\alpha$ - to $\varepsilon$-hydroxylation. In general, shorter carbon-chains reduced the decarboxylation activity, going in hand with an increase of conversion. However, fatty acids shorter than C12:0 were not tested so far, while C20:0 was only poorly accepted by the enzyme (Table 4, entry 5, conv. $<1 \%$ ). Sequence alignment of $\mathrm{P} 450_{\mathrm{SP} \alpha}, \mathrm{P} 450_{\mathrm{BS} \beta}, \mathrm{P} 450_{\mathrm{OleT}}$, and $\mathrm{P} 450_{\mathrm{MP}}$ showed that $\mathrm{H} 85$, might play a significant role for decarboxylation activity, as it is only present in $\mathrm{P}^{4} 50_{\mathrm{OleT}}$. To enhance decarboxylation of $\mathrm{P} 450_{\mathrm{MP}}$ its methionine at the respective position was altered $(\mathrm{M} 96 \mathrm{H})$ and the resulting variant was tested for conversion of C12:0, C14:0, and C16:0. However the M96H variant gave only poor conversions (Table 4 , entries $6-8,<1 \%$ ) [65].

\section{In-chain Hydroxylation}

While the hydroxylation of the $\alpha$-position of fatty acids is simplified by the carboxylic acid moiety, which also gives a handle for hydroxylation of the $\beta$-position, hydroxylation further away requires specific control of the conformation of the side chain. Consequently, in most cases, a range of positions get hydroxylated (Table 5). In this chapter hydroxylation at positions between the $\omega$ - and $\alpha / \beta$-position of fatty acids will be discussed.

\subsection{CYP1, CYP2, CYP77, CYP81, CYP96, CYP703 and CYP709 from Eukaryotes}

The best-investigated CYPs for in-chain fatty acid hydroxylation are from bacterial sources, the most prominent being CYP102A1 from Bacillus megaterium. Nevertheless, a range of catalysts with promising regioselectivities originates from other sources [32]. The eukaryotic classes CYP1 and CYP2 demonstrate in-chain hydroxylation with sometimes outstanding selectivity, such as the strict $\omega-6$ hydroxylation of C12:0 by Cyp2M1 from Oncorhynchus mykiss (Rainbow trout; Table 5, entry 24) [83]. CYP classes from plants, that perform in-chain hydroxylation of fatty acids include CYP77, CYP81, CYP96, CYP703, and CYP709 $[32,33]$. Two selective orthologues that were heterologously expressed in yeast are CYP703 from Arabidopsis thaliana (mainly active on carbon number 7 of C10:0, C12:0, and C14:0) [98] and CYP81B1 from Helianthus tuberosus (carbon number 7 and 8 in C10:0, C12:0, and C14:0) [99]. However, preparative application of (mostly membrane-bound) animal and plant CYPs remains a challenge due to troublesome recombinant expression and the requirement for complex/unknown redox-systems.

\subsection{CYP102}

The enzyme CYP102A1 from Bacillus megaterium (BM3) is special among the CYP family as a $65 \mathrm{kDa}$ diflavin-reductase domain is fused to the $55 \mathrm{kDa} \mathrm{P} 450$ heme domain and therefore no additional redox-system is required (examples for crystal structures, substrate-bound: $1 \mathrm{JPZ}$ and substratefree: $1 \mathrm{BVY}$ ). This fact, plus the enzymes high activity (up to $17,000 \mathrm{~min}^{-1}$ ) [100] and coupling efficiency (up to $>99 \%$ ), render it the most excessively investigated CYP up to date. Similar to most other bacterial CYPs, BM3 enables the hydroxylation at the $\omega-1, \omega-2$, and $\omega-3$ position of fatty acids (C10:0-C18:0) with the highest activity for C15:0 (Table 5, e.g. entry 37 and Fig. 2) [77, 86]. For unsaturated fatty acids from $\mathrm{C}_{12}$ to $\mathrm{C}_{22}$, usually both, in-chain hydroxylation and epoxidation at the $\mathrm{C}=\mathrm{C}$-bond closest to the terminus were found (Fig. 3) [101-103]. The high activity for unsaturated fatty acids and branched fatty acids led to speculations whether these compounds constitute its natural
Table $4 \mathrm{P}^{4} 50_{\mathrm{MP}}$-mediated hydroxylation and decarboxylation of fatty acids, using $\mathrm{H}_{2} \mathrm{O}_{2}$ as the oxidant (CYP152MP from Methylobaterium populi)

\begin{tabular}{llllllllll}
\hline Entry & Enzyme variant & Substrate & Conc. $(\mathrm{mM})$ & Con. $(\%)$ & Alkene $(\%)$ & $\alpha(\%)$ & $\beta(\%)$ & $\gamma, \delta, \varepsilon(\%)$ & Refs. \\
\hline 1 & Wildtype & C12:0 & 0.5 & $>99$ & & 8 & 71 & 21 & {$[65]$} \\
2 & Wildtype & C14:0 & 0.5 & 89 & & 3 & 70 & $27^{\text {a }}$ & {$[65]$} \\
3 & Wildtype & C16:0 & 0.5 & 64 & 24 & 3 & 65 & $7^{\text {b }}$ & {$[65]$} \\
4 & Wildtype & C18:0 & 0.5 & 18 & 38 & 8 & 48 & $5^{\text {b }}$ & {$[65]$} \\
5 & Wildtype & C20:0 & 0.5 & $<1^{\text {c }}$ & & n.r. & n.r. & n.r. & {$[65]$} \\
6 & M96H & C12:0 & 0.5 & $<1^{\text {d }}$ & n.r. & n.r. & n.r. & {$[65]$} \\
7 & M96H & C14:0 & 0.5 & $<1^{\text {d }}$ & n.r. & n.r. & n.r. & {$[65]$} \\
8 & M96H & C16:0 & 0.5 & $<1^{\text {d }}$ & n.r. & n.r. & n.r. & {$[65]$} \\
\hline
\end{tabular}

Conc. substrate concentration, Con. conversion, $n . r$. not reported in the reference

${ }^{\mathrm{a}} \gamma$ - and $\delta$-hydroxylated fatty acid products were detected

${ }^{b} \gamma$-hydroxylated fatty acid products were detected

${ }^{\mathrm{c}}$ Only $\beta$-hydroxylated fatty acid product was detected

${ }^{\mathrm{d}}$ Mostly $\beta$-hydroxylated fatty acid product was detected 


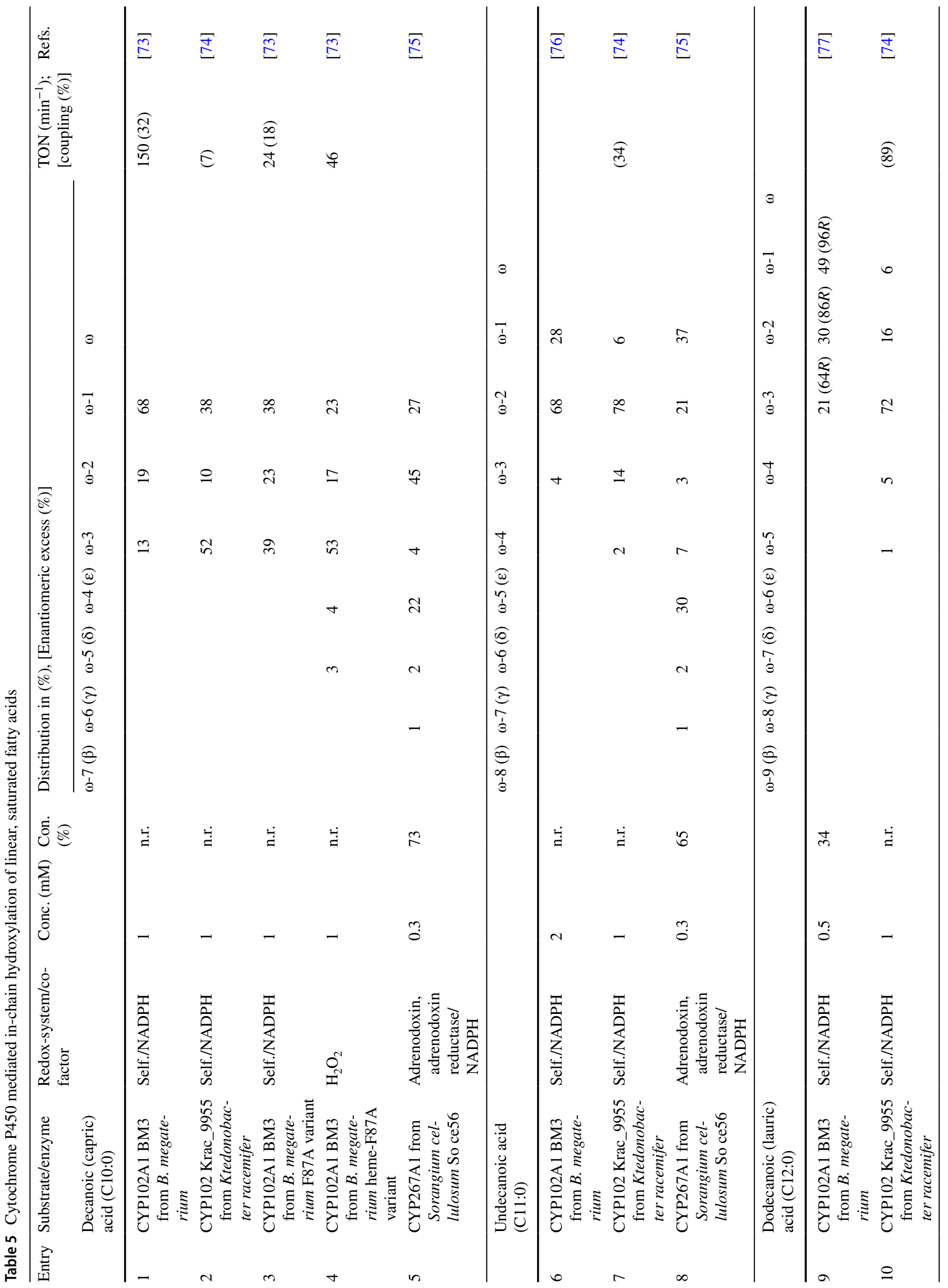




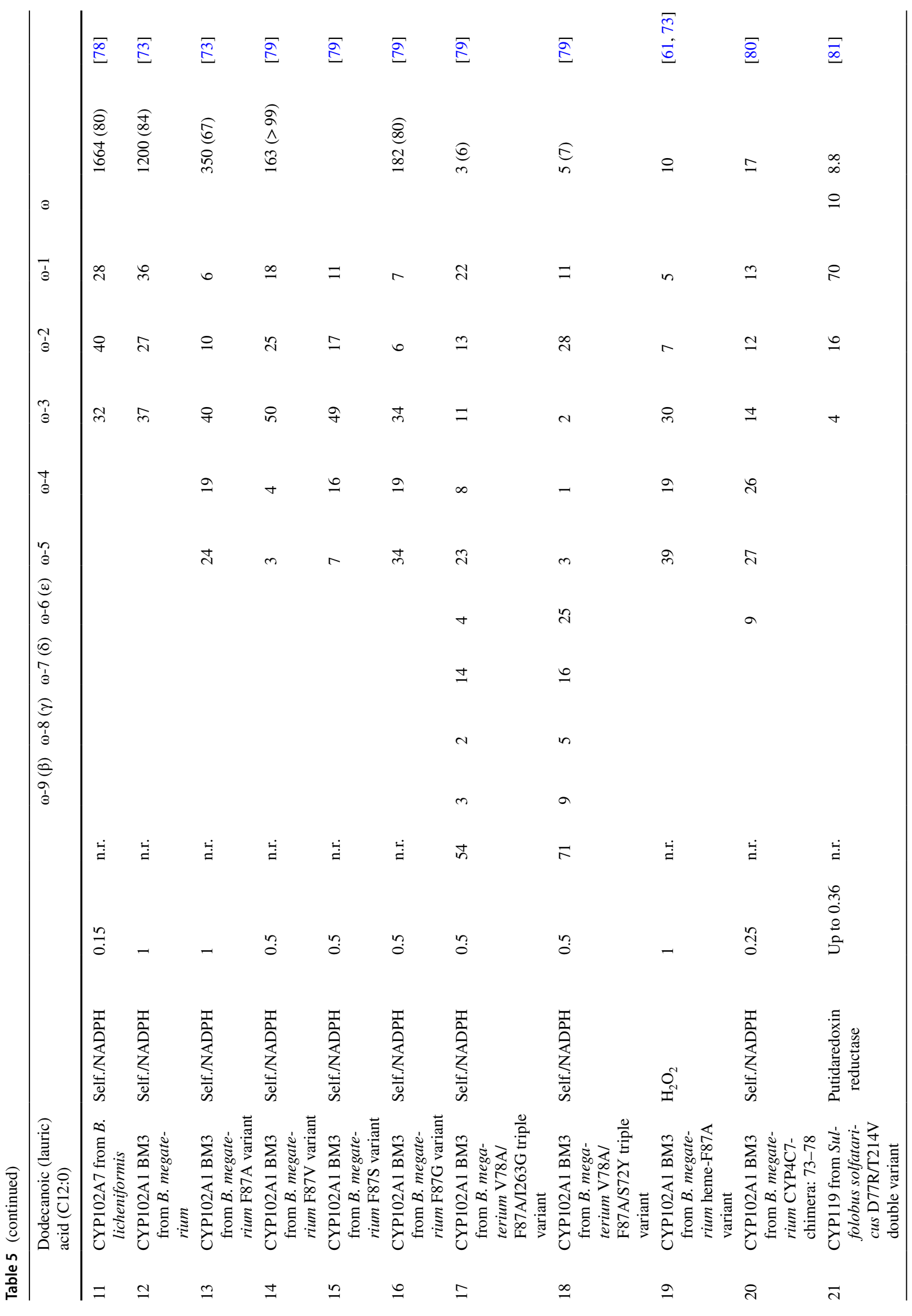




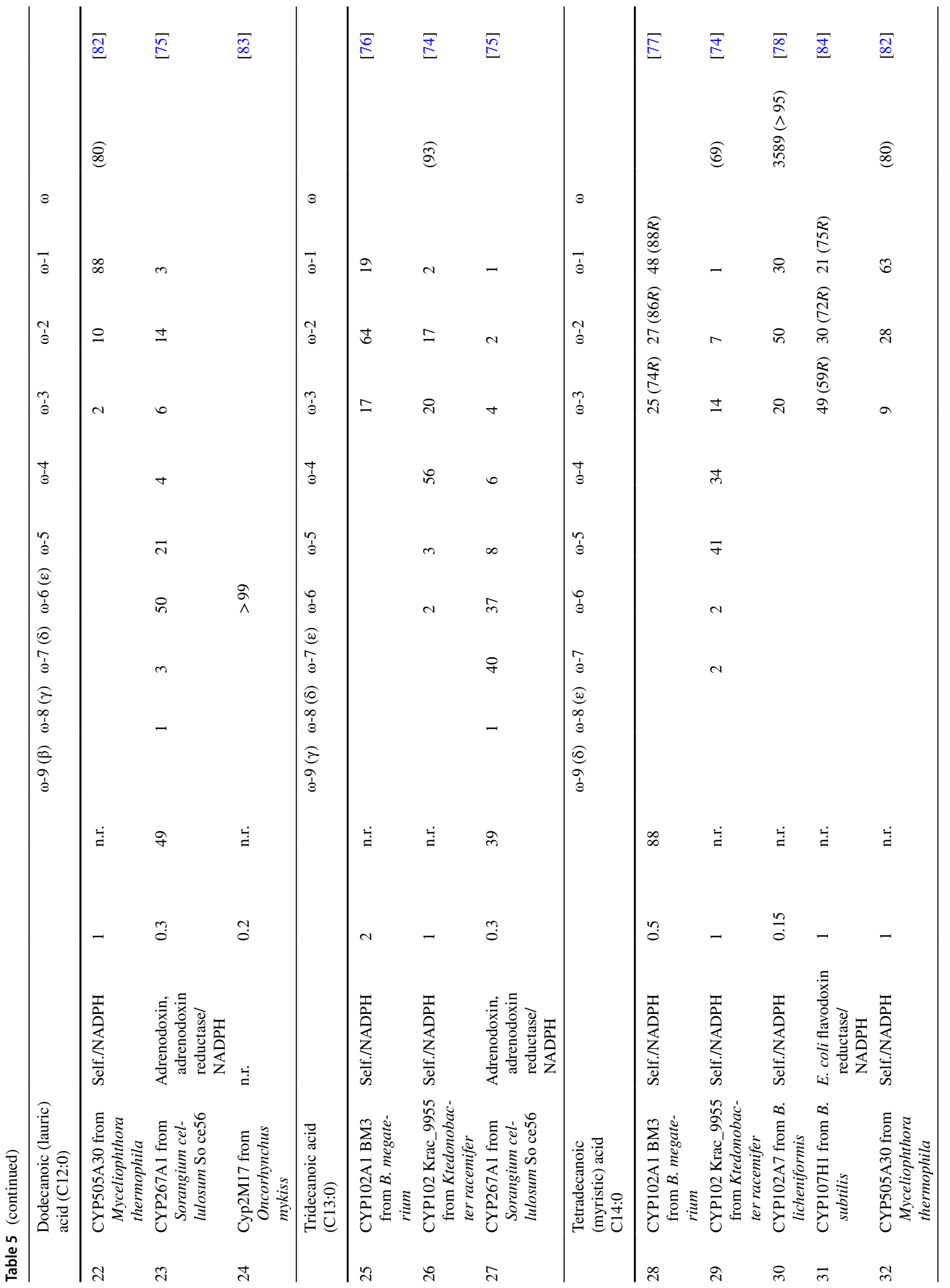




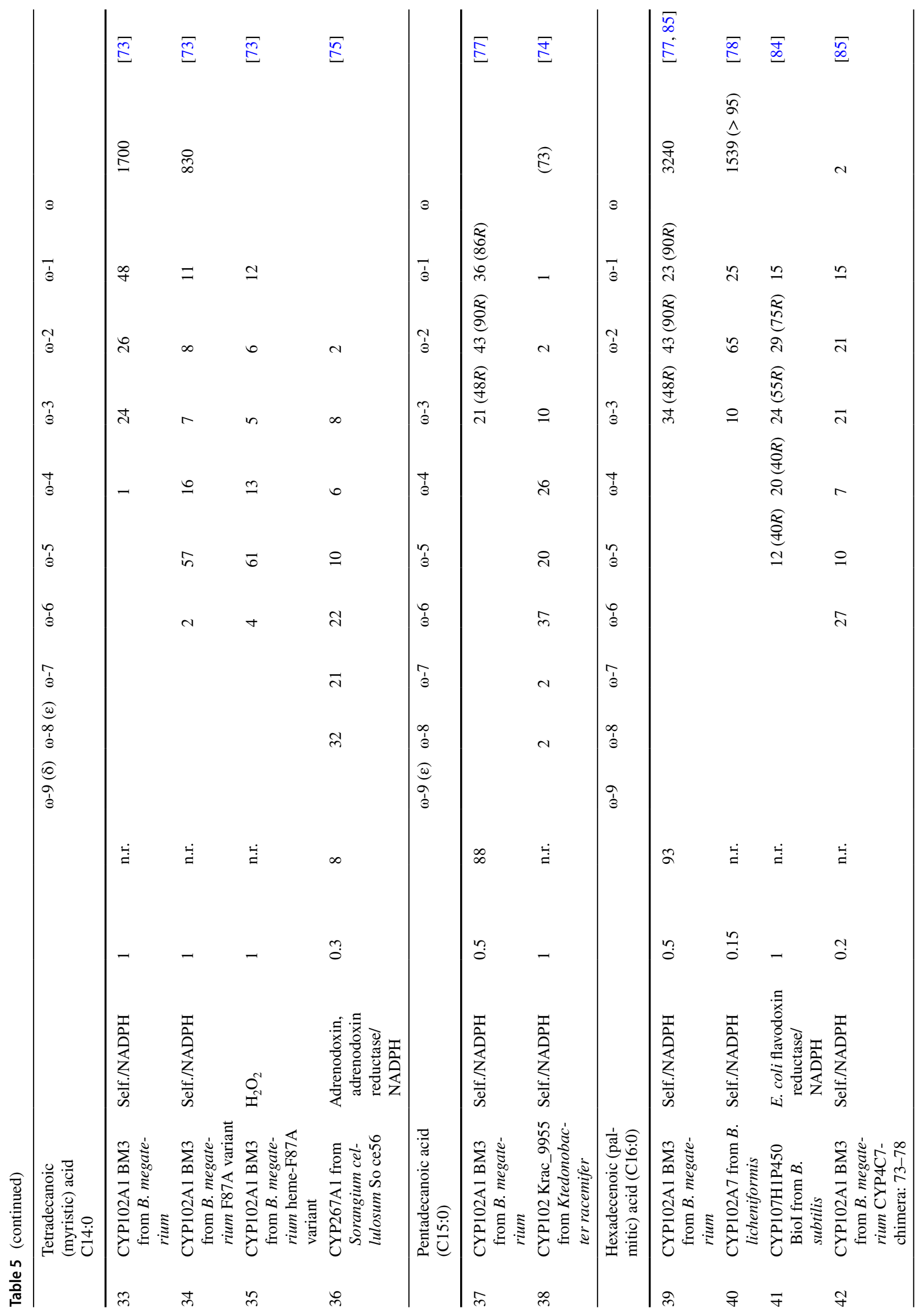




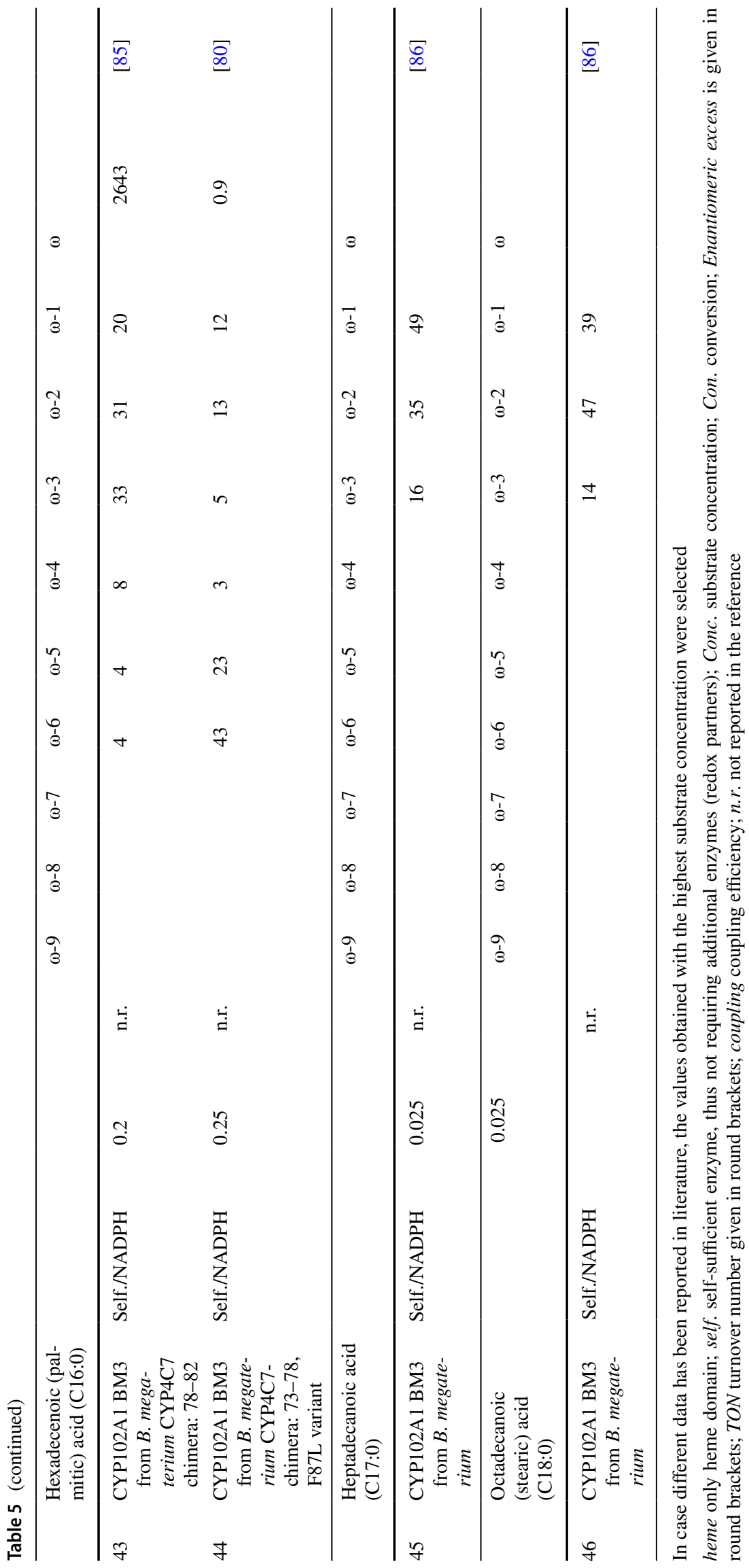



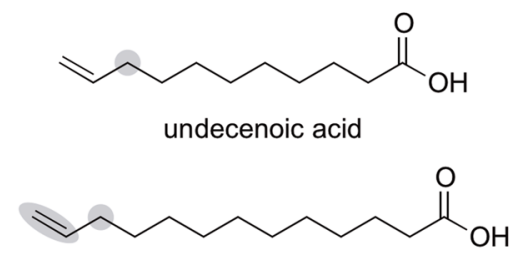

12-tridecenoic acid (C13:1)

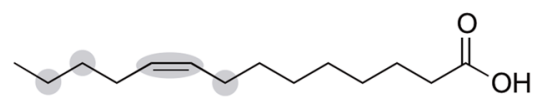

cis-9-tetradecenoic (myristoleic) acid (C14:1)

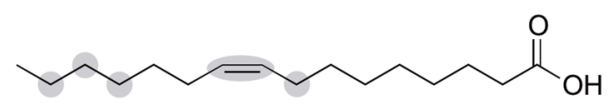

cis-9-hexadecenoic (palmitoleic) acid (C16:1)

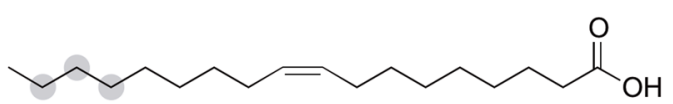

cis-9-octadecenoic (oleic) acid (C18:1)

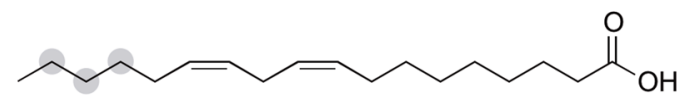

cis, cis-9,12-octadecadienoic (linoleic) acid (C18:2)

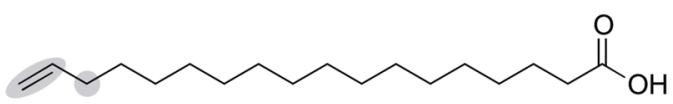

17-octadecenoic acid

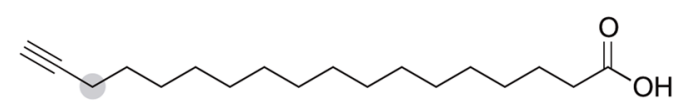

17-octadecynoic acid

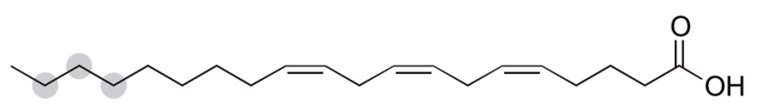

all-cis-5,8,11-eicosatrienoic acid (C20:3)

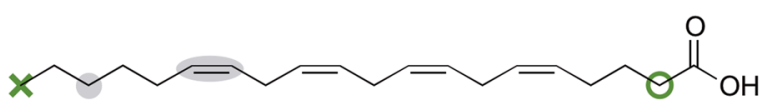

arachidonic acid (C20:4)

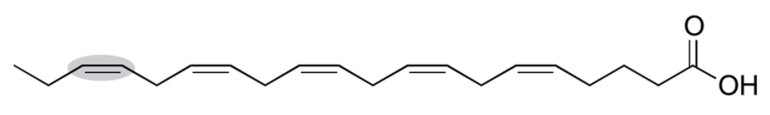

all-cis-5,8,11,14,17-eicosapentaenoic acid (C20:3)

Fig. 3 Positions in unsaturated fatty acids, that have been reported to be functionalized with cytochrome $\mathrm{p} 450 \mathrm{~s}$ by (i) carboxy-terminal hydroxylation, (indicated by a green ring, for details see Table 1), (ii)

substrates (Tables 6, 7) [104, 105]. Interestingly, whereas $\omega-\mathrm{C}=\mathrm{C}$ bonds increased the regioselectivity towards $\omega-2$, probably due to the activated allylic location of hydroxylation (Table 6, entries 2, 3, and 9), a terminal alkyne-group was demonstrated to deactivate the enzyme by forming an adduct with the heme (Table 6, entry 10) $[102,106]$. The self-sufficiency of BM3 and its various reactions inspired the characterization of numerous additional CYP102 members, such as CYP102D1 from Streptomyces avermitiliswhich is the only characterized CYP102 outside the Bacillus family [107], CYP102A7 from Bacillus licheniformis (Table 5, entries 11, 30, and 40, Table 6, entries 8 and 13 and Table 7, entries 5 and 10) [78], and CYP102A2 and CYP102A3, both from Bacillus subtilis [108]. Similar as BM3, these family members prefer unsaturated or branched over saturated fatty acids and catalyze the in-chain hydroxylation of all three positions ( $\omega-1, \omega-2$, and $\omega$ - 3 , e.g. values for CYP102A7 from Bacillus licheniformis, mentioned above). CYP102A5 from Bacillus cereus displays slightly higher selectivity as only the positions $\omega-1, \omega-2$ are transformed (C16:0) [109]. Krac_9955, a recently identified orthologue from Ktedonobacter racemifer DSM44963 breaks the common pattern and additionally shows minor hydroxylation of position $\omega-4$ to $\omega-8$ (Table 5 , entries $2,7,10,26,29$, and 38). In contrast to this, Krac_0936, a CYP102 from the same organism, shows the "classical" pattern for saturated fatty in-chain hydroxylation (indicated by filled grey circles, for details see Table 6) or epoxidation (grey ellipse, see Table 6), and (iii) terminal hydroxylation (indicated by a "x", for details see Table 8)

acids but a higher activity towards oleic, linoleic, palmitoleic and myristoleic acid than Krac_9955, however, with no epoxidation (Table 6, entries 4-7, 11, and 12). Interestingly, Krac_9955 demonstrates some selectivity for allylic positions, as the terminal functionalized 10-undecenoic acid gave perfect selectivity in the allylic position and for myristoleic acid, even the in-chain allylic position was reactive (Table 6, entries 4 and 5) [74].

\subsubsection{Tuning Regio-Selectivity of CYP102A1}

Crystal structures as well as site-directed mutagenesis identified the residues R47 and Y51 to act as an anchor for the substrates carboxylate moiety [100]. A tunnel-shaped substrate pocket connects these residues and the active site, positioning the substrates tail towards the heme. Molecular dynamic simulations and QM/MM calculations demonstrated the closing of the substrate tunnel of BM3 triggered by substrate binding via a significant change of enzyme conformation (movements $>10 \AA$ ) facilitated by hydrogen bonding interactions of P25, E43, and L188 [36, 111]. F87 changes its orientation to shield one side of the substrates terminus and the pro-S $\mathrm{C}-\mathrm{H}$ bonds promoting regioselectivity and controlling the $(R)$-selectivity of the enzyme [111]. A variation of the bulky F87 results (contrary to older reports [112]) in a more relaxed hydroxylation pattern due to the 


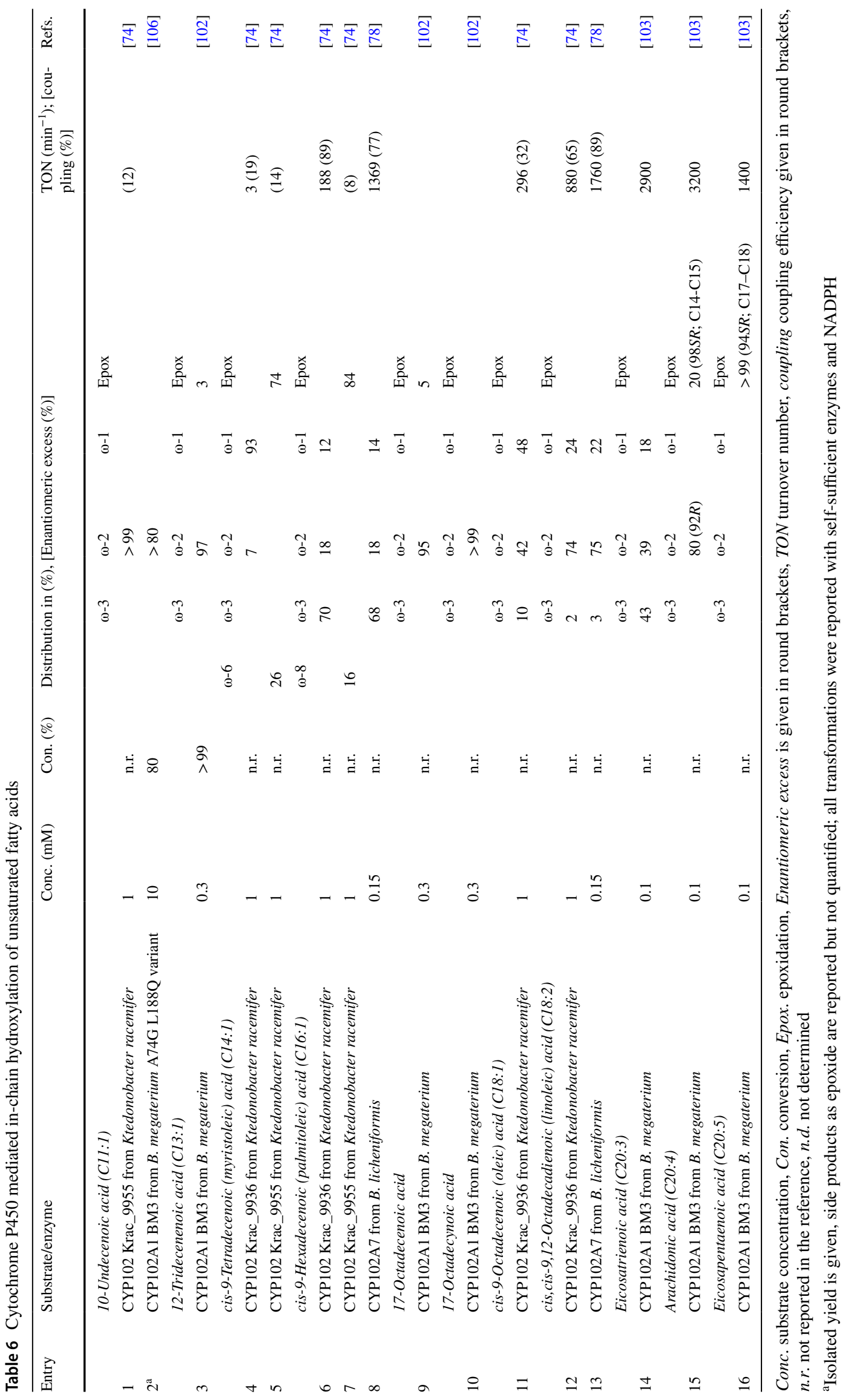




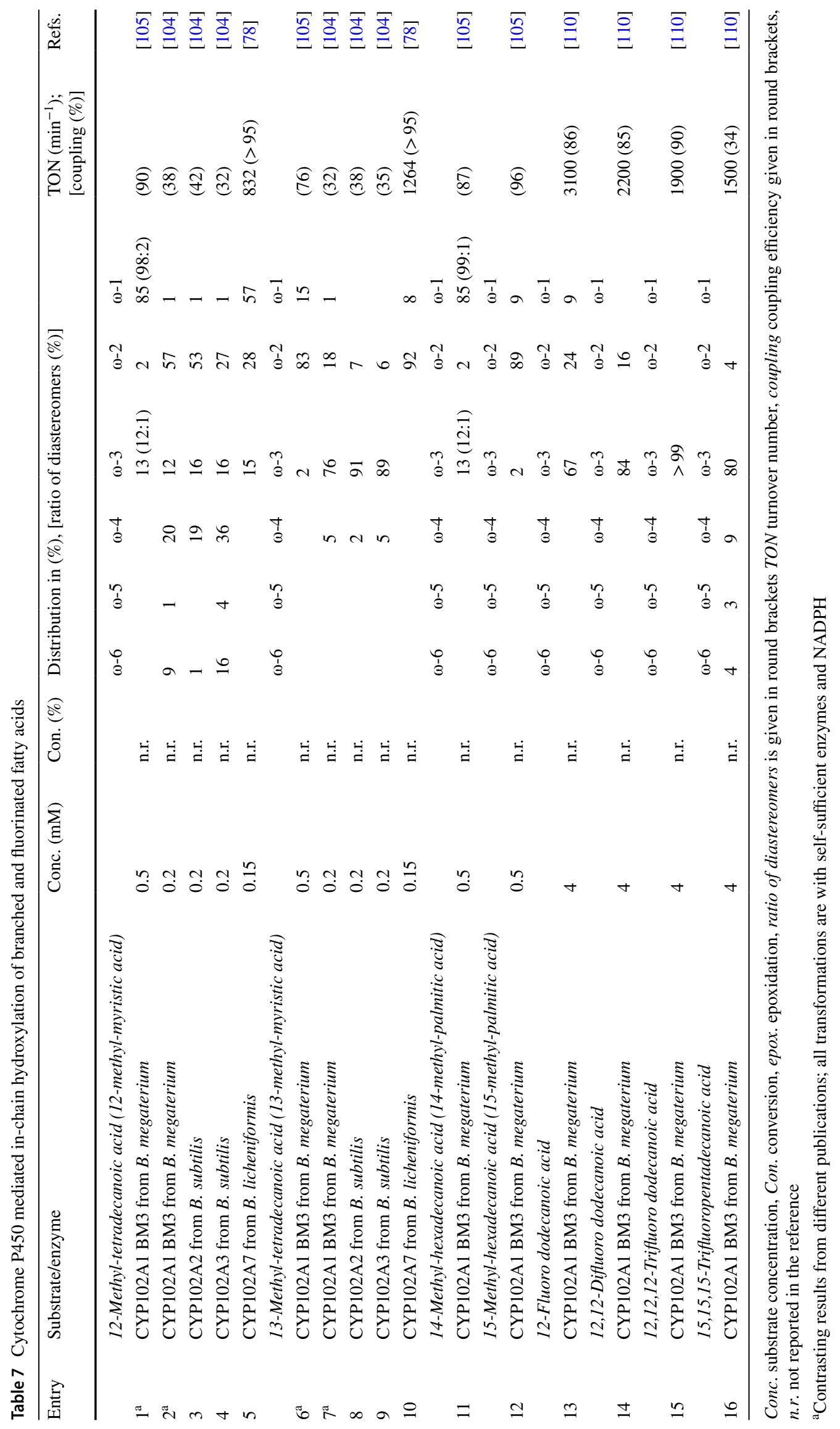


higher flexibility of the substrate terminus within the active site. Therefore, variants $\mathrm{F} 87 \mathrm{~V}$ or $\mathrm{F} 87 \mathrm{~S}$ produced minor amounts of ( $\omega-5)$-hydroxylauric acid (C12:0) and the mutant with an even smaller amino acid (F87A) gave $24 \%$ of the ( $\omega-5)$-hydroxy-product (Table 5, entries 13-16). Similarly, the variant led to a shift in the hydroxylation pattern increasing ( $\omega$-3)-hydroxylation for C10:0 and triggered hydroxylation up to position $\omega-8$ for C14:0 while losing its activity towards the positions $\omega-1$ and $\omega-2$ (Table 5, entries 1, 3, 33 and 34) [73, 79].

Building on the F87A variant of BM3, a systematic approach to alter the enzymes regioselectivity was investigated based on two strategies [79]: (i) The methodical enlargement of the active site in order to allow the substrate more flexibility, therefore increasing the probability of additional substrate binding modes with an altered hydroxylation pattern, and (ii) the introduction of novel substrate binding sites, forcing the substrates configuration to rearrange. Following the first strategy, the active site was enlarged by exchanging V78 to alanine. The resulting variant hydroxylated the positions $\omega-1$ to $\omega-9$ of C12:0. The effect of an additional I263A exchange on regio-selectivity was less pronounced, an additional I263G mutation, however, shifted the hydroxylation pattern further towards the carboxylateterminus of the substrate (Table 5, entry 17). Finally, with the S72Y substitution, a new polar residue was introduced into the apolar substrate tunnel as a potential new anchor for the substrate. Molecular dynamics simulation confirmed that the substrate can bind at either anchor (the new Y72 and the R47/Y51 pair) and predicted that the centre of a substrate binding at the new Y72 is forced closer to the heme. This was supported by a change of the hydroxylation pattern showing $9 \%$ of hydroxylation in position $\omega-9$ (correspond to $\beta$, Table 5, entry 18). Unfortunately, all variants displayed a decrease of activity and coupling efficiency, resulting in only five turnovers per minute and a coupling efficiency of $7 \%$ for the V78A/F87A/S72Y triple variant [79].

In order to pinpoint the effect of L188, which underwent a significant rearrangement upon substrate binding $[36,111]$, the variants of a saturation mutagenesis of this position were evaluated for the hydroxylation of C12:0-C16:0. Whereas the influence of this position onto regioselectivity was minor, especially variants L188Q and L188P demonstrated significantly higher hydroxylation activities [76].

The same position L188, together with A74, F87 and the substrate anchoring site R47 and Y51 was varied to generate a catalyst that promotes regio-, and enantioselective hydroxylation at the allylic position of $\omega$-alkenoic acids and esters. The double-variant A7G/L188Q gave the highest activity for the tested esters, however, the corresponding short chain $\omega$-alkenoic acids were almost not converted. Only the longest tested carboxylic acid, 11-undecenoic acid, was accepted by the variant and in an upscaling $(10 \mathrm{mM})$
(S)-9-hydroxy-undec-10-enoic acid was isolated with $80 \%$ yield (Table 6, entry 2) [106].

An alternative approach to alter BM3s substrate specificity was termed "scanning chimeragenesis" [80]. To transfer the selectivity described for CYP4C7 from Diploptera punctata (cockroach) for the C12-position in farnesol to BM3, the corresponding amino acid residues from a homologous region in $\mathrm{CYP} 4 \mathrm{C} 7$ were transferred into the substrate recognition site of BM3. Besides the effect on the enzymes hydroxylation-selectivity for farnesol, the hydroxylation pattern for C16:0 was shifted further into the chain. Chimera enzyme $\mathrm{C}(73-78)$ displayed a $27 \%$ hydroxylation selectivity on position $\omega-6$, however going in hand with a significant loss of activity. Chimera $\mathrm{C}(78-82)$ on the other hand, retained high activity, however, also the effect onto regioselectivity was not strong (Table 5, entries 42 and 43) [85]. Later also F87 variants were evaluated on both $\mathrm{C} 16: 0$ and C12:0, however, the additional mutation resulted in further loss of activity (Table 5, entry 44) [80].

\subsection{Towards New Fatty Acid Substrates for CYP102A1}

Besides attempts to influence the regioselectivity of BM3, numerous studies focused on broadening the substrate scope of the enzyme. By applying a colorimetric screen using $p$-nitrophenoxy-derivatives ( $p$ NCA) as substrates, BM3 was evolved for increased activity on alkanes in five rounds. The obtained variant also proved to have a two times higher activity for C12:0 and C16:0 [113]. Rational site-directed mutagenesis was applied in order to establish BM3 variants to hydroxylate shorter chain carboxylic acids [114]. Guided by a crystal structure in complex with palmitoleate (C16:1), a series of hydrophobic residues alongside the substrate (L75, L181, I263, L437) were exchanged for residues capable to serve as carboxylate anchor. The L75T/L181 K double mutation increased the enzymes activity for $\mathrm{C} 8: 0$ by a factor of 2.5 to $3256 \mathrm{~min}^{-1}$ and the catalytic efficiency $\left(\mathrm{k}_{\mathrm{cat}} / \mathrm{K}_{\mathrm{M}}\right)$ by a factor of 4 to $165 \mathrm{mmol} \mathrm{min}^{-1}$. The same double mutation improved the wildtype's activity towards C6:0 by an order of magnitude to $2590 \mathrm{~min}^{-1}\left(\mathrm{k}_{\mathrm{cat}} / \mathrm{K}_{\mathrm{M}}=14.6 \mathrm{mmol} \mathrm{min}{ }^{-1}\right)$ and the $\mathrm{L} 181 \mathrm{~K}$ variant was even able to utilize $\mathrm{C} 4: 0$ at an activity of $353 \mathrm{~min}^{-1}$ and $\mathrm{k}_{\mathrm{cat}} / \mathrm{K}_{\mathrm{M}}$ of $3.04 \mathrm{mmol} \mathrm{min}^{-1}$ [114]. A concept entitled "rational evolution", combining structurebased rational design with directed evolution was applied to increase $\mathrm{BM} 3 \mathrm{~s}$ performance in the hydroxylation of the medium chain acids C10:0 and C8:0. Eight mutation sites (P25, V26, R47, Y51, S72, A47, L188, and M354) were randomized and evaluated using a photometric assay with the corresponding $p$ NCA as substrate. Again, F87A served as the starting point. The final five-fold variant V26T/R47F/ A74G/L188K/F87A efficiently utilized $\omega$ - $p$-nitrophenol octanoic acid (8-pNCA) [115]. 
A range of branched-chain fatty acids were tested with CYP102 family members (Fig. 4). The orthologue from Bacillus megaterium as well as the CYP102A2 and CYP102A3 from Bacillus subtilis converted sub-terminally methylated $\mathrm{C}_{14}$ and $\mathrm{C}_{16}$ fatty acids (Table 7) [104, 105]. BM3 and its A74G/F87V/L188Q triple variant were utilized to hydroxylate several multi-methylated fatty acid derivatives (as well as ketones, alcohols; and esters) with activities up to 1204 turnovers per minute [104]. The technology was applied for the synthesis of the $\mathrm{C} 3-\mathrm{C} 11$ fragment of borrelidin at $13 \mathrm{mM}$ substrate concentration (the corresponding methyl-ester) with $34 \%$ (184 mg) isolated product after purification [30].

Fatty acids possessing fluoro atoms in $\omega$-position were demonstrated to stabilize the transition states and therefore enhance reaction rates. Already 12 -fluorododecanoic acid was transformed at comparable rates as C15:0. Adding more fluoro atoms to the terminus led to a higher selectivity for $\omega$-3 hydroxylation (>99\% for 12,12,12-trifluorododecanoic acid; Table 7, entries 13-16, and Fig. 5) [110].

\subsubsection{Towards New Electron Sources for CYP102A1}

One of the major drawbacks of CYPs is the dependence on one equivalent of the cofactor NADPH and the uncoupling, thus the loss of reduction equivalents by the peroxide shunt by producing $\mathrm{H}_{2} \mathrm{O}_{2}$, which is harmful to both, enzyme and heme. An elegant solution to overcome these limitations is the reversal of the peroxide shunt, allowing to shortcut the catalytic cycle and to utilize $\mathrm{H}_{2} \mathrm{O}_{2}$ as cheap electron source. In initial studies; the amino acid F87 was identified as a key residue to enable this reaction in BM3, as its alanine variant utilizes $\omega$ - $p$-nitrophenol dodecanoic acid (12- $p$ NCA) with 162 turnovers per minute in the presence of $\mathrm{H}_{2} \mathrm{O}_{2}$ as electron source $\left(493 \mathrm{~min}^{-1}\right.$ with $\left.\mathrm{NADPH} / \mathrm{O}_{2}\right)$ [116]. When the system was applied to fatty acids also a truncated version of BM3, consisting only of the enzyme's heme-domain, was evaluated. Activities of up to $48 \mathrm{~min}^{-1}$ (C10:0) were obtained while the hydroxylation pattern was shifted to the substrate's center due to the F87A mutation (Table 5, entries 4,19 , and 35) [73]. This variant was later applied as starting point for five rounds of directed evolution towards higher peroxygenase activity using $12-p \mathrm{NCA}$ as substrate. The final variant contained 10 mutations (I58V, F78A, H100R, F107L, A135S, M145V, N239H, S274T, K434E, and V446I) was termed "21B3" and showed a 20 -fold higher activity for the substrate screened. The peroxygenase activity was increased also for C12:0. However, to a lower extent from 10 to $50 \mathrm{~min}^{-1}$ [61]. By a QM/MM-guided approach residues W96 and F405 in the 10-fold variant were identified to be oxidizable by $\mathrm{H}_{2} \mathrm{O}_{2}$, which allowed the design of a more stable variant retaining the activity (single or double variants: W96A, F405L or W96A/F405L) [59].

\subsubsection{Challenges in Productivity of CYP102A1}

Although BM3 possesses high activity and is self-sufficient, examples for the BM3-catalyzed hydroxylation of fatty acids at preparative levels remain scarce. Challenges to overcome are the poor substrate solubility, low coupling efficiencies and the formation of side products due to over-oxidation or multiple oxidations [117]. Careful balance of the available (dissolved) oxygen in the system was demonstrated to be crucial for selective single-oxidations with an E. coli designer cell expressing BM3 and a pGEc47-fatty acid uptake system. Whereas at $5 \%$ dissolved oxygen a productivity of $3 \mathrm{U} \mathrm{g}^{-1}$ cell dry weight (cdw) allows the production of $2 \mathrm{mM}$ mono-hydroxylated C15:0, oxygen-excess resulted
Fig. 4 In-chain positions in branched fatty acids, that have been reported to be hydroxylated by cytochrome $\mathrm{P} 450$ s (indicated with grey circles, for details see Table 7)

Fig. 5 In-chain positions in fluorinated fatty acids, that have been reported to be hydroxylated by cytochrome P450s (indicated with grey circles, for details see Table 7)

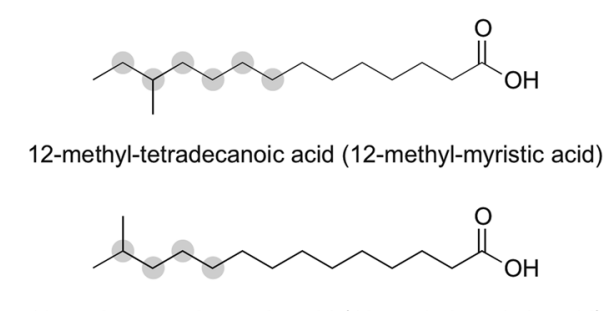

13-methyl-tetradecanoic acid (13-methyl-myristic acid)
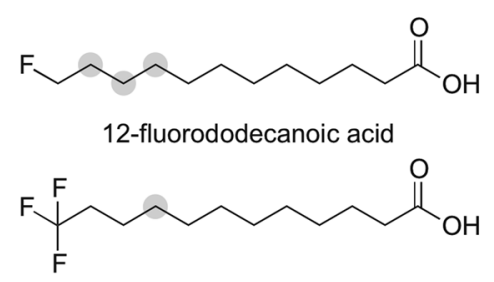

12,12,12-trifluorododecanoic acid

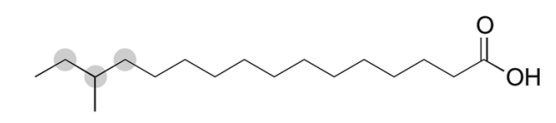

14-methyl-hexadecanoic acid (14-methyl-palmitic acid)

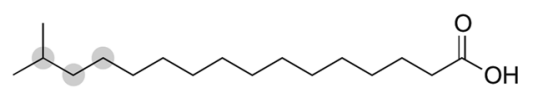

15-methyl-hexadecanoic acid (15-methyl-palmitic acid)

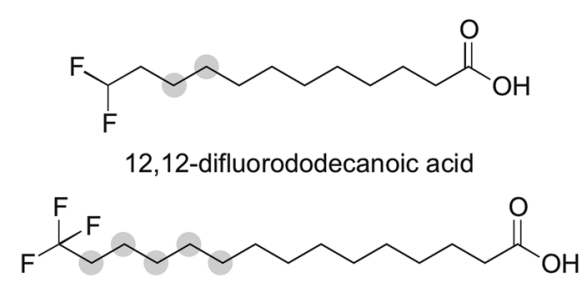

15,15,15-trifluoropentadecanoic acid 
in a higher productivity ( $3.5 \mathrm{U} \mathrm{g}^{-1} \mathrm{cdw}, 4 \mathrm{mM}$ of products) at cost of selectivity, as numerous over-oxidation products were identified [118]. For improving the solubility of C12:0 in an aqueous system cyclodextrins and co-solvents were employed. In a setup consisting of a NADH-dependent BM3 variant (R966D and W1046S), a FDH cofactor recycling system and a catalase a total turnover of 37,000 was achieved while the addition of $\mathrm{CH}_{3} \mathrm{CN}(2 \% \mathrm{v} / \mathrm{v})$ increased this value to 47,000 . The addition of CAVASOLW7M Pharma, a randomly methylated beta-cyclodextrin allowed to reach a total turnover number of 60,000 and substrate concentration of $50 \mathrm{mM}$ with $67 \%$ conversion of C12:0 [119].

\subsection{CYP107}

CYP107H1 from Bacillus subtilis ( $\mathrm{P} 450_{\mathrm{BioI}}$ ) catalyzes the in-chain hydroxylation of fatty acids up to position $\omega-5$ (C14:0 and C16:0; Table 5, entries 31 and 41) [84]. The enzyme is involved in biotin biosynthesis by producing the building block pimelic acid (heptanedioic acid) by $\mathrm{C}-\mathrm{C}$ cleavage of acyl-carrier-protein (ACP) bond fatty acids via vicinal hydroxylation and over-oxidation [120].

\subsection{CYP119}

A thermostable P450 enzyme from the CYP119 family, isolated from the bacterium Sulfolobus solfataricus (crystal structure, e.g.: $1 \mathrm{IO} 7$ at $1.5 \AA$ ) is able to bind C8:0-C20:0 fatty acids and showed a moderate selectivity for the $\omega-1$ hydroxylation of C12:0. With a D77R/T214V double variant both, the hydroxylation rate and the utilization of the redox partner putidaredoxin increased without alteration of the hydroxylation pattern (Table 5, entry 21) [81].

\subsection{CYP267}

CYP267A1 from Sorangium cellulosum (So ce56) is a CYP family member in which the conserved phenylalanine from the cysteine-pocket is replaced by leucine. The enzyme is active on $\mathrm{C} 8: 0$ to $\mathrm{C} 15: 0$ with the highest conversion reported for C10:0 and hydroxylates between $\omega-1$ and $\omega-9$. The hydroxylation pattern shifts towards the carboxylate terminus with increasing chain length (Table 5, entries 5, 8, 23, 27, and 36). Mutation of L366 to the conserved phenylalanine resulted in the "classical" selectivity for $\omega-1$ to $\omega-3$ [75].

\subsection{CYP505}

The eukaryotic CYP505 family consists of membranebound CYPs that originate from fungi. The heme-domain is fused with a diflavin-reductase domain, similar as for BM3, rendering the enzyme self-sufficient. CYP505A1 from Fusarium oxysporum $\left(\mathrm{P}^{4} 0_{\text {foxy }}\right)$ facilitates the hydroxylation of C6:0 to C16:0 fatty acids at the positions $\omega-1$ to $\omega$ - 3 (for $\mathrm{C} 10: 0$ and $\mathrm{C} 12: 0$ position $\omega-1$ is most favored, for $\mathrm{C} 11: 0$ position $\omega-2$ ) and suffers in contrast to BM3 from substrate inhibition with fatty acid substrates longer than C13 [121]. Recently, CYP505A30 from the thermostable Myceliophthora thermophila was characterized as fatty acid hydroxylase. The enzyme demonstrated a strong selectivity for position $\omega-1$, with minor amounts of hydroxylation at $\omega-2$ and $\omega-3$ in C12:0 and C14:0 (Table 5, entries 22 and 32) [82].

\section{Terminal Hydroxylation}

Given the higher bond strength of terminal $\mathrm{C}-\mathrm{H}$ bonds (prim-C-H) as compared to in-chain $(\mathrm{sec}-\mathrm{C}-\mathrm{H})$ or allylic positions, $\omega$-selectivity requires a very specific substrate orientation which forces the carbon-chain terminus close to the heme-iron [20]. A range of CYP classes have evolved to perform this challenging reaction, including orthologues from eukaryotic sources such as enzymes from vertebrates (CYP4), plants (CYP76, CYP78, CYP86, CYP94, CYP96) [32], and fungi (CYP52), as well as prokaryotic sources (CYP153) [36]. In addition to these P450s that are naturally active towards the terminus, other enzymes were converted into $\omega$-hydroxylases by site-directed mutagenesis and directed evolution.

\subsection{CYP102}

For CYP102A1 BM3 from B. megaterium terminally $p$-nitrophenoxy-functionalized ( $p$ NCA) fatty acids were used as substrates in a spectrophotometric assay to evolve the enzyme to utilize short-chain fatty acids [122], however, this did not result in $\omega$-selectivity for free fatty acids. A directed evolution approach allowed to produce BM3 variants with up to 11 mutations with a $\omega$-selectivity of $74 \%$ (6th generation variant 29E12: Q55P, N70S, F87I, M185T, A197V, K202R, V216A, M237L, N239T, I263F, A328V, see Table 8, entry 13). Especially the varied positions close to the substrate (F87, I263, and A328) contributed to the regioselectivity. Unfortunately, at high cell densities, overoxidation to the dicarboxylic acid increased [123].

\subsection{CYP153}

Based on the activity of CYP153 family members to $\omega$-hydroxylate both, alkanes and alcohols, with a chain length of $\mathrm{C}_{5}-\mathrm{C}_{16}$, it was assumed that the enzyme class might also be active on other polar compounds such as fatty acids [124]. Consequently, the orthologues CYP153A34 from Polaromonas sp., CYP153A16 from Mycobacterium marinum and CYP153A33 from Marinobacter aquaeolei were tested on fatty acids. CYP153A34 gave only low 
Table 8 Cytochrome P450 mediated terminal hydroxylation of fatty acids

\begin{tabular}{|c|c|c|c|c|c|c|c|c|}
\hline \multirow[t]{2}{*}{ Entry } & Substrate/enzyme & Redox system & Conc. (mM) & $\begin{array}{l}\text { Con. } \\
(\%)\end{array}$ & $\omega(\%)$ & sub. $(\%)$ & TON $\left(\min ^{-1}\right)$ & Refs. \\
\hline & \multicolumn{8}{|l|}{ Octanoic (capryl) acid (C8:0) } \\
\hline \multirow[t]{2}{*}{1} & $\begin{array}{l}\text { CYP153A33 from Marinobacter } \\
\text { aquaeolei G307A variant }\end{array}$ & $\begin{array}{l}\text { Putidaredoxin reductase }(\mathrm{CamA}) \\
\text { and putidaredoxin }(\mathrm{CamB})\end{array}$ & 1 & 20 & 98 & 2 & 2.55 & [124] \\
\hline & \multicolumn{8}{|l|}{ Decanoic (capric) acid (C10:0) } \\
\hline \multirow[t]{2}{*}{2} & $\begin{array}{l}\text { CYP153A33 from Marinobacter } \\
\text { aquaeolei }\end{array}$ & $\begin{array}{r}\text { Putidaredoxin reductase }(\mathrm{CamA}) \text {, } \\
\text { putidaredoxin }(\mathrm{CamB}) / \mathrm{NADPH}\end{array}$ & 0.2 & 52 & $>99$ & & n.r. & [124] \\
\hline & \multicolumn{8}{|l|}{ Dodecanoic (lauric) acid (C12:0) } \\
\hline 3 & $\begin{array}{l}\text { CYP153A33 from Marinobacter } \\
\text { aquaeolei }\end{array}$ & $\begin{array}{r}\text { Putidaredoxin reductase }(\mathrm{CamA}) \text {, } \\
\text { putidaredoxin }(\mathrm{CamB}) / \mathrm{NADPH}\end{array}$ & 0.2 & 64 & $97^{\mathrm{a}}$ & $1^{\mathrm{a}}$ & n.r. & [124] \\
\hline 4 & $\begin{array}{l}\text { CYP153A33 from Marinobacter } \\
\text { aquaeolei G307A variant - BM3 } \\
\text { fusion protein }\end{array}$ & $\begin{array}{l}\text { Self-sufficient (BM3 diflavin-reduc- } \\
\text { tase)/NADPH }\end{array}$ & 50 & 12 & $>95$ & & n.r. & [125] \\
\hline 5 & CYP52A21 from Candida albicans & $\begin{array}{l}\text { Rat cytochrome } \mathrm{P} 450 \text { reductase/ } \\
\text { NADPH }\end{array}$ & n.r. & 53 & 92 & 8 & 30 & [126] \\
\hline 6 & CYP4A1 from rat & $\begin{array}{l}\text { Human cytochrome } \mathrm{P} 450 \text { reductase, } \\
\text { cytochrome } \mathrm{b} / \mathrm{NADPH}\end{array}$ & 0.1 & n.r. & 98 & 2 & 649 & [127] \\
\hline \multirow[t]{2}{*}{7} & CYP4A11 from human & $\begin{array}{l}\text { Human cytochrome } \mathrm{P} 450 \text { reductase, } \\
\text { cytochrome }_{\mathrm{b}} / \mathrm{NADPH}\end{array}$ & 0.1 & n.r. & 94 & 6 & 42 & [127] \\
\hline & \multicolumn{8}{|l|}{ Tetradecanoic (myristic) acid C14:0 } \\
\hline 8 & CYP76A3 from Petunia hybrida & $\begin{array}{l}\text { From Saccharomyces cerevisiae } \\
\text { host }\end{array}$ & 5 & n.r. & $>99$ & & n.r. & [128] \\
\hline 9 & $\begin{array}{l}\text { CYP153A33 from Marinobacter } \\
\text { aquaeolei G307A variant }\end{array}$ & $\begin{array}{l}\text { Putidaredoxin reductase }(\mathrm{CamA}), \\
\text { putidaredoxin }(\mathrm{CamB}) / \mathrm{NADPH}\end{array}$ & 1 & 69 & 97 & 3 & 7.5 & [124] \\
\hline 10 & CYP52A21 from Candida albicans & $\begin{array}{l}\text { Rat cytochrome } \mathrm{P} 450 \text { reductase/ } \\
\text { NADPH }\end{array}$ & n.r. & 47 & 91 & 9 & n.r. & [126] \\
\hline 11 & CYP4A1 from rat & $\begin{array}{l}\text { Human cytochrome } \mathrm{P} 450 \text { reductase, } \\
\text { cytochrome } \mathrm{b}_{\mathrm{b}} / \mathrm{NADPH}\end{array}$ & 0.1 & n.r. & 75 & 25 & 230 & [127] \\
\hline \multirow[t]{2}{*}{12} & CYP4A11 from human & $\begin{array}{l}\text { Human cytochrome } \mathrm{P} 450 \text { reductase, } \\
\text { cytochrome } \mathrm{b}_{\mathrm{b}} / \mathrm{NADPH}\end{array}$ & 0.1 & n.r. & 80 & 20 & 50 & [127] \\
\hline & \multicolumn{8}{|l|}{ Hexadecenoic (palmitic) acid (C16:0) } \\
\hline 13 & $\begin{array}{l}\text { CYP102A1 BM3 from B. megate- } \\
\text { rium variant } 29 \mathrm{E} 12\end{array}$ & Self-sufficient/NADPH & 5 & n.r. & $74^{\mathrm{a}}$ & $18^{\mathrm{a}}$ & 84 & [123] \\
\hline 14 & CYP52A21 from Candida albicans & $\begin{array}{l}\text { Rat cytochrome } \mathrm{P} 450 \text { reductase/ } \\
\text { NADPH }\end{array}$ & n.r. & 15 & 93 & 7 & n.r. & [126] \\
\hline 15 & CYP4A1 from rat & $\begin{array}{l}\text { Human cytochrome } \mathrm{P} 450 \text { reductase, } \\
\text { cytochrome } \mathrm{b}_{\mathrm{b}} / \mathrm{NADPH}\end{array}$ & 0.1 & n.r. & 50 & 50 & 60 & [127] \\
\hline \multirow[t]{2}{*}{16} & CYP4A11 from human & $\begin{array}{l}\text { Human cytochrome } \mathrm{P} 450 \text { reductase, } \\
\text { cytochrome } \mathrm{b}_{\mathrm{b}} \text { /NADPH }\end{array}$ & 0.1 & n.r. & 69 & 31 & 10 & [127] \\
\hline & \multicolumn{8}{|l|}{ Arachidonic acid (C20:4) } \\
\hline 17 & CYP4A1 from rat & $\begin{array}{l}\text { Human cytochrome } \mathrm{P} 450 \text { reductase, } \\
\text { cytochrome } / \text { /NADPH }\end{array}$ & 0.1 & n.r. & 86 & 14 & 6 & [127] \\
\hline
\end{tabular}

Conc. substrate concentration, Con. conversion, $\omega \omega$-hydroxylation, sub. in-chain hydroxylation, TON turnover number, n.r. not reported in the reference

${ }^{a}$ Rest to $100 \%$ : products due to over-oxidation

conversions for saturated short chain fatty acids (C8:0 to C13:0), the other two candidates showed broader activity. The best-performing enzyme, CYP153A33 was active for all substrates (C9:0-C20:0 and unsaturated $\mathrm{C}_{14}-\mathrm{C}_{18}$ fatty acids;
Table 8, entries 2 and 3) except C8:0. However, a G307A variant enabled also this activity (Table 8 , entries 1 and 9). Residue L354 was shown to influence regioselectivity as its L354I variant already gave $76 \%$ of $\omega-1$ hydroxylation [124]. 
The fusion-protein of CYP153A33 G307A variant with the diflavin-reductase domain of CYM102A1 BM3 was demonstrated to be superior to other redox-systems and allowed $12 \%$ conversion of $\mathrm{C} 12: 0$ at $10 \mathrm{~g} \mathrm{~L}^{-1}$ employing $E$. coli cells (Table 8, entry 4). Productivity was enhanced when the corresponding methyl ester was supplied as substrate $\left(4 \mathrm{~g} \mathrm{~L}^{-1}\right)$ [125]. A G307A/S233G double substitution identified by semi-rational design allowed to double the overall activity for medium-chain fatty acids [129].

\subsection{CYP52}

Members of the CYP52 family have been isolated from yeasts and catalyze the terminal hydroxylation of fatty acids and alkanes. CYP52A21 from Candida albicans was demonstrated to convert fatty acids $\mathrm{C} 12: 0$ to $\mathrm{C} 16: 0$ to the corresponding $\omega$-hydroxy acid with selectivities of up to $93 \%$ (Fig. 2; Table 8, entries 5, 10 and 14). For $\omega, \omega, \omega-$ trideuterated lauric acid (C12:0) a shift towards $(\omega-1)$ hydroxylation was obtained, and 12-halogenated lauric acids (iodo-, bromo, and chloro-) were converted to 12-oxo-lauric acid via hydrolysis of the oxohalonium species formed by halogen-oxidation [126]. An engineered Candida tropicalis strain was demonstrated to hydroxylate $\mathrm{C} 12: 0$ (supplied as the corresponding methyl ester) with a productivity of more than $160 \mathrm{~g} \mathrm{~L}^{-1}$, and less than $5 \%$ formation of the corresponding dicarboxylic acid [130].

\subsection{CYP76}

The family members originate from plants. CYP76A3 from Petunia hybrid was expressed in Saccharomyces cerevisiae and among 21 tested fatty acids, the enzyme was exclusively active on myristic acid (C14:0), producing 14-hydroxy myristate (Fig. 2; Table 8, entry 8) [128].

\subsection{CYP4}

CYP4 members originate from mammalian sources and are known for their ability to catalyze fatty acid hydroxylation preferably at the $\omega$-terminal carbon. The family has been characterized in detail, however, reports with elevated substrate concentrations in the millimolar $(\mathrm{mM})$ range are rare [20]. Examples for the substrate profile of CYP4A1 from rat and CYP4A11 from human are given in Table 8 (entries 6, $7,11,12,15,16$, and 17) [127].

\section{Outlook}

Due to the variety of reactions catalyzed by cytochrome P450 enzymes, the family has significant potential for synthetic applications. Whereas self-sufficient P450s show the highest turnover numbers and coupling efficiency up to now, fusion to redox partners or modern electron donor systems allow also other CYPs to run with increased efficiency $[94,125,131,132]$. Drawbacks of the CYP family are poor (regio-)selectivities, low productivities, uncoupling, and the dependence on NADPH as reducing agent $[14,17$, 18]. The latter may be overcome by $\mathrm{P} 450$ peroxygenases, which utilize hydrogen peroxide as oxidant [23]. Additionally, uncoupling is diminished when using peroxygenases since the autoxidation shunt is avoided and $\mathrm{H}_{2} \mathrm{O}_{2}$ produced by the peroxide shunt can be used in the next cycle (Fig. 1). So far just a few natural P450 peroxygenases were reported, which limits the choice of interesting candidates. Several mutagenesis approaches showed the possibility to transform conventional P450s into peroxygenases $[59,61]$. Therefore, peroxygenases have high potential; however, since elevated $\mathrm{H}_{2} \mathrm{O}_{2}$-concentrations are harmful for both, the enzyme and its heme-cofactor [58-60], stable variants [59, 61] and variants rescuing the heme-cofactor are highly desired. Furthermore, alternative in situ $\mathrm{H}_{2} \mathrm{O}_{2}$-production methods $[69,133]$ or feeding of low amounts of $\mathrm{H}_{2} \mathrm{O}_{2}$ may be exploited.

To enhance the regio-, and stereo-selectivities of P450s, site-directed and directed evolution approaches might lead to ideal catalysts [123]. Reaction engineering represents another challenge for industrial-scale P450s applications, as many interesting substrates display low solubility in the aqueous reaction system. Therefore, the addition of co-solvent, two-liquid-phase reaction conditions or neat reaction systems have to be exploited.

Due to the compatibility of P450s and their redox partners, the most efficient way to use conventional P450 enzymes is in artificial biosynthetic pathways to produce valuable secondary metabolites or as whole cell catalysts. Furthermore, the application of P450s with other enzymes or heterogeneous catalysts in vitro will give access to valuable molecules.

In conclusion, enzymatic systems involving the cytochrome P450 family reached a certain maturity and are ready for synthetic applications. Their main activity, regioand stereoselective $\mathrm{C}-\mathrm{H}$ activation is intriguing and especially in connection with fatty acids without precedence.

Acknowledgements This study was financed by the Austrian FFG, BMWFJ, BMVIT, SFG, Standortagentur Tirol and ZIT through the Austrian FFG-COMET- Funding Program as well as by Aroma Chemical Services International S.A. Open access funding provided by University of Graz.

Open Access This article is distributed under the terms of the Creative Commons Attribution 4.0 International License (http://creativeco mmons.org/licenses/by/4.0/), which permits unrestricted use, distribution, and reproduction in any medium, provided you give appropriate credit to the original author(s) and the source, provide a link to the Creative Commons license, and indicate if changes were made. 


\section{References}

1. Lamb DC, Lei L, Warrilow AG, Lepesheva GI, Mullins JG, Waterman MR, Kelly SL (2009) The first virally encoded cytochrome P450. J Virol 83:8266-8269

2. Grogan G (2011) Cytochromes P450: exploiting diversity and enabling application as biocatalysts. Curr Opin Chem Biol 15:241-248

3. Fasan R (2012) Tuning P450 enzymes as oxidation catalysts. ACS Catal 2:647-666

4. Torres Pazmino DE, Winkler M, Glieder A, Fraaije MW (2010) Monooxygenases as biocatalysts: classification, mechanistic aspects and biotechnological applications. J Biotechnol 146:9-24

5. Whitehouse CJC, Bell SG, Wong L-L (2012) P 450BM3 (CYP102A1): connecting the dots. Chem Soc Rev 41:1218-1260

6. Dennig A, Kuhn M, Tassoti S, Thiessenhusen A, Gilch S, Bulter T, Haas T, Hall M, Faber K (2015) Oxidative decarboxylation of short-chain fatty acids to 1-alkenes. Angew Chem Int Ed 54:8819-8822

7. Oliw EH, Bylund J, Herman C (1996) Bisallylic hydroxylation and epoxidation of polyunsaturated fatty acids by cytochrome P450. Lipids 31:1003-1021

8. Ahr H, King L, Nastainczyk W, Ullrich V (1982) The mechanism of reductive dehalogenation of halothane by liver cytochrome P450. Biochem Pharmacol 31:383-390

9. Rahimtula AD, O'Brien PJ (1975) Hydroperoxide dependent O-dealkylation reactions catalyzed by liver microsomal cytochrome P450. Biochem Biophys Res Commun 62:268-275

10. Volz TJ, Rock DA, Jones JP (2002) Evidence for two different active oxygen species in cytochrome P450 BM3 mediated sulfoxidation and $\mathrm{N}$-dealkylation reactions. J Am Chem Soc 124:9724-9725

11. Coelho PS, Brustad EM, Kannan A, Arnold FH (2013) Olefin cyclopropanation via carbene transfer catalyzed by engineered cytochrome P450 enzymes. Science 339:307-310

12. Prier CK, Zhang RK, Buller AR, Brinkmann-Chen S, Arnold FH (2017) Enantioselective, intermolecular benzylic C-H amination catalysed by an engineered iron-haem enzyme. Nat Chem 9:629-634

13. Kan SBJ, Lewis RD, Chen K, Arnold FH (2016) Directed evolution of cytochrome $\mathrm{c}$ for carbon-silicon bond formation: bringing silicon to life. Science 354:1048-1051

14. Lundemo MT, Woodley JM (2015) Guidelines for development and implementation of biocatalytic $\mathrm{P} 450$ processes. Appl Microbiol Biotechnol 99:2465-2483

15. Urlacher VB, Girhard M (2012) Cytochrome P450 monooxygenases: an update on perspectives for synthetic application. Trends Biotechnol 30:26-36

16. Sakaki T (2012) Practical application of cytochrome P450. Biol Pharm Bull 35:844-849

17. Hou CT (2009) Biotechnology for fats and oils: new oxygenated fatty acids. New Biotechnol 26:2-10

18. Eiben S, Kaysser L, Maurer S, Kühnel K, Urlacher VB, Schmid RD (2006) Preparative use of isolated CYP102 monooxygenases: a critical appraisal. J Biotechnol 124:662-669

19. Kim KR, Oh DK (2013) Production of hydroxy fatty acids by microbial fatty acid-hydroxylation enzymes. Biotechnol Adv 31:1473-1485

20. Johnston JB, Ouellet H, Podust LM, Ortiz de Montellano PR (2011) Structural control of cytochrome P450-catalyzed omegahydroxylation. Arch Biochem Biophys 507:86-94

21. Babot ED, del Río JC, Kalum L, Martínez AT, Gutiérrez A (2013) Oxyfunctionalization of aliphatic compounds by a recombinant peroxygenase from Coprinopsis cinerea. Biotechnol Bioeng 110:2323-2332

22. Gutierrez A, Babot ED, Ullrich R, Hofrichter M, Martinez AT, del Rio JC (2011) Regioselective oxygenation of fatty acids, fatty alcohols and other aliphatic compounds by a basidiomycete heme-thiolate peroxidase. Arch Biochem Biophys 514:33-43

23. Wang Y, Lan D, Durrani R, Hollmann F (2017) Peroxygenases en route to becoming dream catalysts: what are the opportunities and challenges? Curr Opin Chem Biol 37:1-9

24. Holic R, Yazawa H, Kumagai H, Uemura H (2012) Engineered high content of ricinoleic acid in fission yeast Schizosaccharomyces pombe. Appl Microbiol Biotechnol 95:179-187

25. Broun P, Boddupalli S, Somerville C (1998) A bifunctional oleate 12-hydroxylase: desaturase from Lesquerella fendleri. Plant J 13:201-210

26. Coon MJ (2005) Omega oxygenases: nonheme-iron enzymes and P450 cytochromes. Biochem Biophys Res Commun 338:378-385

27. Schrewe M, Magnusson AO, Willrodt C, Bühler B, Schmid A (2011) Kinetic analysis of terminal and unactivated C-H bond oxyfunctionalization in fatty acid methyl esters by monooxygenase-based whole-cell biocatalysis. Adv Synth Catal 353:3485-3495

28. Andreou A, Brodhun F, Feussner I (2009) Biosynthesis of oxylipins in non-mammals. Prog Lipid Res 48:148-170

29. Hamberg M, Ponce de Leon I, Rodriguez MJ (2005) Castresana $\mathrm{C} \alpha$-dioxygenases. Biochem Biophys Res Commun 338:169-174

30. Theurer M, El Baz Y, Koschorreck K, Urlacher VB, Rauhut G, Baro A, Laschat S (2011) Chemoenzymatic synthesis of the C3C11-fragment of borrelidin. Eur J Org Chem 2011:4241-4249

31. Sono M, Roach MP, Coulter ED, Dawson JH (1996) Heme-containing oxygenases. Chem Rev 96:2841-2888

32. Kandel S, Sauveplane V, Olry A, Diss L, Benveniste I, Pinot F (2006) Cytochrome P450-dependent fatty acid hydroxylases in plants. Phytochem Rev 5:359-372

33. Bak S, Beisson F, Bishop G, Hamberger B, Höfer R, Paquette S, Werck-Reichhart D (2011) Cytochromes P450. The Arabidopsis Book 9:e0144

34. Salaun JP, Helvig C (1995) Cytochrome P450-dependent oxidation of fatty acids. Drug Metabol Drug Interact 12:261-283

35. Van BINA, Groeneboer S, Saerens K, Soetaert W (2011) The role of cytochrome $\mathrm{P} 450$ monooxygenases in microbial fatty acid metabolism. FEBS J 278:206-221

36. Hlavica P, Lehnerer M (2010) Oxidative biotransformation of fatty acids by cytochromes P450: predicted key structural elements orchestrating substrate specificity, regioselectivity and catalytic efficiency. Curr Drug Metab 11:85-104

37. Vidt DG, Bergfeld WF (1997) Cosmetic use of alpha-hydroxy acids. Clec Clin J Med 64:327-329

38. Joo Y-C, Oh D-K (2012) Lipoxygenases: potential starting biocatalysts for the synthesis of signaling compounds. Biotechnol Adv 30:1524-1532

39. Kurtzman CP, Vesonder RF, Smiley MJ (1973) Formation of extracellular C14-C18 2-D-hydroxy fatty acids by species of Saccharomycopsis. Appl Microbiol 26:650-652

40. Sjögren J, Magnusson J, Broberg A, Schnürer J, Kenne L (2003) Antifungal 3-hydroxy fatty acids from Lactobacillus plantarum MiLAB 14. Appl Environ Microbiol 69:7554-7557

41. Black BA, Zannini E, Curtis JM, Gänzle MG (2013) Antifungal hydroxy fatty acids produced during sourdough fermentation: microbial and enzymatic pathways, and antifungal activity in bread. Appl Environ Microbiol 79:1866-1873

42. Thomas D, Ito T (1969) The revised structure of the peptide antibiotic esperin, established by mass spectrometry. Tetrahedron 25:1985-1990

43. Wasserman HH, Keggi JJ, McKeon JE (1962) The structure of serratamolide 1-3. J Am Chem Soc 84:2978-2982 
44. Vining L, Taber W (1962) Isariin, a new depsipeptide from Isaria cretacea. Can J Chem 40:1579-1584

45. Carballeira NM, Shalabi F, Negron V (1989) 2-Hydroxy fatty acids from marine sponges 2 . The phospholipid fatty acids of the caribbean sponges Verongula gigantea and Aplysina archeri. Lipids 24:229-232

46. Carballeira NM, Shalabi F, Reyes M (1994) New 2-hydroxy fatty acids in the Caribbean urchin Tripneustes esculentus. J Nat Prod 57:614-619

47. Tulloch AP, Spencer JFT (1966) Fermentation of long chain compounds by Torulopsis magnoliae III. Preparation of dicarboxylic acids from hydroxy fatty acid sophorosides. J Am Oil Chem Soc 43:153-156

48. Sun Y, Zeng W, Benabbas A, Ye X, Denisov I, Sligar SG, Du J, Dawson JH, Champion PM (2013) Investigations of heme ligation and ligand switching in cytochromes P450 and P420. Biochemistry 52:5941-5951

49. Ciaramella A, Minerdi D, Gilardi G (2017) Catalytically selfsufficient cytochromes $\mathrm{P} 450$ for green production of fine chemicals. Rend Fis Acc Lincei 28:169-181

50. Girvan HM, Munro AW (2016) Applications of microbial cytochrome $\mathrm{P} 450$ enzymes in biotechnology and synthetic biology. Curr Opin Chem Biol 31:136-145

51. Moktali V, Park J, Fedorova-Abrams ND, Park B, Choi J, Lee Y-H, Kang S (2012) Systematic and searchable classification of cytochrome $\mathrm{P} 450$ proteins encoded by fungal and oomycete genomes. BMC Genom 13:525-525

52. Nelson DR, Koymans L, Kamataki T, Stegeman JJ, Feyereisen R, Waxman DJ, Waterman MR, Gotoh O, Coon MJ, Estabrook RW et al (1996) P450 superfamily: update on new sequences, gene mapping, accession numbers and nomenclature. Pharmacogenetics 6:1-42

53. Ramanan R, Dubey KD, Wang B, Mandal D, Shaik S (2016) Emergence of function in P450-proteins: a combined quantum mechanical/molecular mechanical and molecular dynamics study of the reactive species in the $\mathrm{H}_{2} \mathrm{O}_{2}$-dependent cytochrome $\mathrm{P} 450 \mathrm{SP} \alpha$ and Its regio- and enantioselective hydroxylation of fatty acids. J Am Chem Soc 138:6786-6797

54. Denisov IG, Makris TM, Sligar SG, Schlichting I (2005) Structure and chemistry of cytochrome P450. Chem Rev 105:2253-2277

55. Meunier B, de Visser SP, Shaik S (2004) Mechanism of oxidation reactions catalyzed by cytochrome P450 enzymes. Chem Rev 104:3947-3980

56. Bernhardt R (1995) Cytochrome P450: structure, function, and generation of reactive oxygen species. In: Bernhardt $R$ (ed) Reviews of physiology biochemistry and pharmacology. Springer, Berlin, vol 127, pp 137-221

57. Shoji O, Watanabe Y (2014) Peroxygenase reactions catalyzed by cytochromes P450. J Biol Inorg Chem 19:529-539

58. Karuzina II, Archakov AI (1994) Hydrogen peroxide-mediated inactivation of microsomal cytochrome $\mathrm{P} 450$ during monooxygenase reactions. Free Radical Biol Med 17:557-567

59. Vidal-Limón A, Águila S, Ayala M, Batista CV, VazquezDuhalt R (2013) Peroxidase activity stabilization of cytochrome $\mathrm{P} 450 \mathrm{BM} 3$ by rational analysis of intramolecular electron transfer. J Inorg Biochem 122:18-26

60. Conner KP, Woods CM, Atkins WM (2011) Interactions of cytochrome P450s with their ligands. Arch Biochem Biophys 507:56-65

61. Cirino PC, Arnold FH (2003) A self-sufficient peroxide-driven hydroxylation biocatalyst. Angew Chem Int Ed 42:3299-3301

62. Matsunaga I, Sumimoto T, Kusunose E, Ichihara K (1998) Phytanic acid $\alpha$-hydroxylation by bacterial cytochrome P450. Lipids 33:1213-1216
63. Girhard M, Schuster S, Dietrich M, Durre P, Urlacher VB (2007) Cytochrome $\mathrm{P} 450$ monooxygenase from Clostridium acetobutylicum: a new alpha-fatty acid hydroxylase. Biochem Biophys Res Commun 362:114-119

64. Matsunaga I, Ueda a, Sumimoto T, Ichihara K, Ayata M, Ogura $H$ (2001) Site-directed mutagenesis of the putative distal helix of peroxygenase cytochrome P450. Arch Biochem Biophys 394:45-53

65. Amaya JA, Rutland CD, Makris TM (2016) Mixed regiospecificity compromises alkene synthesis by a cytochrome P450 peroxygenase from Methylobacterium populi. J Inorg Biochem 158:11-16

66. Matsunaga I, Kusunose E, Yano I, Ichihara K (1994) Separation and partial characterization of soluble fatty acid $\alpha$-hydroxylase from Sphingomonas paucimobilis. Biochem Biophys Res Commun 201:1554-1560

67. Matsunaga I, Yokotani N, Gotoh O, Kusunose E, Yamada M, Ichihara K (1997) Molecular cloning and expression of fatty acid alpha-hydroxylase from Sphingomonas paucimobilis. J Biol Chem 272:23592-23596

68. Fujishiro T, Shoji O, Nagano S, Sugimoto H, Shiro Y, Watanabe Y (2011) Crystal Structure of $\mathrm{H}_{2} \mathrm{O}_{2}$-dependent cytochrome $\mathrm{P} 450 \mathrm{SP}$ with its bound fatty acid substrate: insight into the regioselective hydroxylation of fatty acids at the alpha-position. J Biol Chem 286:29941-29950

69. Gandomkar S, Dennig A, Dordic A, Hammerer L, Pickl M, Haas T, Hall M, Faber K (2017) Biocatalytic oxidative cascade for the conversion of fatty acids to alpha-ketoacids via internal $\mathrm{H}_{2} \mathrm{O}_{2}$ recycling. Angew Chem Int Ed. https://doi.org/10.1002/ anie.201710227

70. Matsunaga I, Sumimoto T, Ueda A, Kusunose E, Ichihara K (2000) Fatty acid-specific, regiospecific, and stereospecific hydroxylation by cytochrome P450 (CYP152B1) from Sphingomonas paucimobilis: substrate structure required for $\alpha$-hydroxylation. Lipids 35:365-371

71. Lee D-S, Yamada A, Sugimoto H, Matsunaga I, Ogura H, Ichihara K, Adachi S-i, Park S-Y, Shiro Y (2003) Substrate recognition and molecular mechanism of fatty acid hydroxylation by cytochrome P450 from Bacillus subtilis: crystallographic, spectroscopic, and mutational studies. J Biol Chem 278:9761-9767

72. Rude MA, Baron TS, Brubaker S, Alibhai M, Del Cardayre SB, Schirmer A (2011) Terminal olefin (1-alkene) biosynthesis by a novel p450 fatty acid decarboxylase from Jeotgalicoccus species. Appl Environ Microbiol 77:1718-1727

73. Cirino PC, Arnold FH (2002) Regioselectivity and activity of cytochrome P450 BM-3 and mutant F87A in reactions driven by hydrogen peroxide. Adv Synth Catal 344:932-937

74. Munday SD, Maddigan NK, Young RJ, Bell SG (2016) Characterisation of two self-sufficient CYP102 family monooxygenases from Ktedonobacter racemifer DSM44963 which have new fatty acid alcohol product profiles. Biochim Biophys Acta 1860:1149-1162

75. Khatri Y, Hannemann F, Girhard M, Kappl R, Hutter M, Urlacher VB, Bernhardt R (2015) A natural heme-signature variant of CYP267A1 from Sorangium cellulosum So ce56 executes diverse $\omega$-hydroxylation. FEBS J 282:74-88

76. Jang H-H, Shin S-M, Ma SH, Lee G-Y, Joung YH, Yun C-H (2016) Role of Leu188 in the fatty acid hydroxylase activity of CYP102A1 from Bacillus megaterium. J Mol Catal B 133:35-42

77. Cryle MJ, De Voss JJ (2007) Facile determination of the absolute stereochemistry of hydroxy fatty acids by GC: application to the analysis of fatty acid oxidation by a P450BM3 mutant. Tetrahedron 18:547-551

78. Dietrich M, Eiben S, Asta C, Do TA, Pleiss J, Urlacher VB (2008) Cloning, expression and characterisation of CYP102A7, a 
self-sufficient P450 monooxygenase from Bacillus licheniformis. Appl Microbiol Biotechnol 79:931-940

79. Dietrich M, Do TA, Schmid RD, Pleiss J, Urlacher VB (2009) Altering the regioselectivity of the subterminal fatty acid hydroxylase P450 BM-3 towards $\gamma$ - and $\delta$-positions. J Biotechnol 139:115-117

80. Chen CK, Shokhireva T, Berry RE, Zhang H, Walker FA (2008) The effect of mutation of F87 on the properties of CYP102A1CYP4C7 chimeras: altered regiospecificity and substrate selectivity. J Biol Inorg Chem 13:813-824

81. Koo LS, Immoos CE, Cohen MS, Farmer PJ, Ortiz de Montellano PR (2002) Enhanced electron transfer and lauric acid hydroxylation by site-directed mutagenesis of CYP119. J Am Chem Soc 124:5684-5691

82. Baker GJ, Girvan HM, Matthews S, McLean KJ, Golovanova M, Waltham TN, Rigby SEJ, Nelson DR, Blankley RT, Munro AW (2017) Expression, purification, and biochemical characterization of the flavocytochrome P450 CYP505A30 from Myceliophthora thermophila. ACS Omega 2:4705-4724

83. Yang YH, Wang JL, Miranda CL, Buhler DR (1998) CYP2M1: cloning, sequencing, and expression of a new cytochrome $\mathrm{P} 450$ from rainbow trout liver with fatty acid (omega-6)-hydroxylation activity. Arch Biochem Biophys 352:271-280

84. Cryle MJ, Matovic NJ, De Voss JJ (2003) Products of cytochrome P450BioI (CYP107H1)-catalyzed oxidation of fatty acids. Org Lett 5:3341-3344

85. Murataliev MB, Trinh LN, Moser LV, Bates RB, Feyereisen R, Walker FA (2004) Chimeragenesis of the fatty acid binding site of cytochrome P450BM3: replacement of residues 73-84 with the homologous residues from the insect cytochrome $\mathrm{P} 450$ CYP4C7. Biochemistry 43:1771-1780

86. Miura Y, Fulco AJ (1975) w-1,w-2 and w-3 hydroxylation of long-chain fatty acids, amides and alcohols by a soluble ezyme system from Bacillus megaterium. Biochim Biophys Acta 388:305-317

87. Matsunaga I, Ueda A, Fujiwara N, Sumimoto T, Ichihara K (1999) Characterization of the ybdT gene product of Bacillus subtilis: novel fatty acid $\beta$-hydroxylating cytochrome P450. Lipids 34:841-846

88. Torres E, Hayen H, Niemeyer CM (2007) Evaluation of cytochrome $\mathrm{P} 450$ (BSbeta) reactivity against polycyclic aromatic hydrocarbons and drugs. Biochem Biophys Res Commun 355:286-293

89. Shoji O, Fujishiro T, Nakajima H, Kim M, Nagano S, Shiro Y, Watanabe Y (2007) Hydrogen peroxide dependent monooxygenations by tricking the substrate recognition of cytochrome P450BSbeta. Angew Chem Int Ed 46:3656-3659

90. Shoji O, Fujishiro T, Nagano S, Tanaka S, Hirose T, Shiro Y, Watanabe Y (2010) Understanding substrate misrecognition of hydrogen peroxide dependent cytochrome P450 from Bacillus subtilis. J Biol Inorg Chem 15:1331-1339

91. Matsunaga I, Sumimoto T, Ayata M, Ogura H (2002) Functional modulation of a peroxygenase cytochrome P450: novel insight into the mechanisms of peroxygenase and peroxidase enzymes. FEBS Lett 528:90-94

92. Lee DS, Yamada A, Matsunaga I, Ichihara K, Adachi S-i, Park S-Y, Shiro Y (2002) Crystallization and preliminary X-ray diffraction analysis of fatty-acid hydroxylase cytochrome P450BSbeta from Bacillus subtilis. Acta Crystallogr D 58:687-689

93. Dennig A, Kurakin S, Kuhn M, Dordic A, Hall M, Faber K (2016) Enzymatic oxidative tandem decarboxylation of dioic acids to terminal dienes. Eur J Org Chem 2016:3473-3477

94. Liu Y, Wang C, Yan J, Zhang W, Guan W, Lu X, Li S (2014) Hydrogen peroxide-independent production of $\alpha$-alkenes by OleTJE P450 fatty acid decarboxylase. Biotechnol Biofuels 7:28
95. Belcher J, McLean KJ, Matthews S, Woodward LS, Fisher K, Rigby SE, Nelson DR, Potts D, Baynham MT, Parker DA et al (2014) Structure and biochemical properties of the alkene producing cytochrome P450 OleTJE (CYP152L1) from the Jeotgalicoccus sp. 8456 bacterium. J Biol Chem 289:6535-6550

96. Matthews S, Belcher JD, Tee KL, Girvan HM, McLean KJ, Rigby SE, Levy CW, Leys D, Parker DA, Blankley RT et al (2017) Catalytic determinants of alkene production by the cytochrome $\mathrm{P} 450$ peroxygenase OleTJE. J Biol Chem. https://doi.org/10.1074/jbc. M116.762336

97. Grant JL, Hsieh CH, Makris TM (2015) Decarboxylation of fatty acids to terminal alkenes by cytochrome P450 compound I. J Am Chem Soc 137:4940-4943

98. Morant M, Jorgensen K, Schaller H, Pinot F, Moller BL, WerckReichhart D, Bak S (2007) CYP703 is an ancient cytochrome P450 in land plants catalyzing in-chain hydroxylation of lauric acid to provide building blocks for sporopollenin synthesis in pollen. Plant Cell 19:1473-1487

99. Cabello-Hurtado F, Batard Y, Salaün J-P, Durst F, Pinot F, Werck-Reichhart D (1998) Cloning, expression in yeast, and functional characterization of CYP81B1, a plant cytochrome P450 that catalyzes in-chain hydroxylation of fatty acids. J Biol Chem 273:7260-7267

100. Noble MA, Miles CS, Chapman SK, Lysek DA, MacKay AC, Reid GA, Hanzlik RP, Munro AW (1999) Roles of key active-site residues in flavocytochrome P450 BM3. Biochem J 339:371-379

101. Ruettinger RT, Fulco AJ (1981) Epoxidation of unsaturated fatty acids by a soluble cytochrome P-450-dependent system from Bacillus megaterium. J Biol Chem 256:5728-5734

102. Shirane N, Sui Z, Peterson JA, Ortiz de Montellano PR (1993) Cytochrome P450BM-3 (CYP102): regiospecificity of oxidation of omega-unsaturated fatty acids and mechanism-based inactivation. Biochemistry 32:13732-13741

103. Capdevila JH, Wei S, Helvig C, Falck JR, Belosludtsev Y, Truan G, Graham-Lorence SE, Peterson JA (1996) The highly stereoselective oxidation of polyunsaturated fatty acids by cytochrome P450BM-3. J Biol Chem 271:22663-22671

104. Budde M, Morr M, Schmid RD, Urlacher VB (2006) Selective hydroxylation of highly branched fatty acids and their derivatives by CYP102A1 from Bacillus megaterium. ChemBioChem 7:789-794

105. Cryle MJ, Espinoza RD, Smith SJ, Matovic NJ, De VJJ: (2006) Are branched chain fatty acids the natural substrates for P450(BM3)?. Chem Commun 2353-2355

106. Neufeld K, Henssen B, Pietruszka J (2014) Enantioselective allylic hydroxylation of omega-alkenoic acids and esters by $\mathrm{P} 450$ BM3 monooxygenase. Angew Chem Int Ed 53:13253-13257

107. Choi K-Y, Jung E, Jung D-H, Pandey BP, Yun H, Park H-Y, Kazlauskas RJ, Kim B-G (2012) Cloning, expression and characterization of CYP102D1, a self-sufficient P450 monooxygenase from Streptomyces avermitilis. FEBS J 279:1650-1662

108. Gustafsson MCU, Roitel O, Marshall KR, Noble MA, Chapman SK, Pessegueiro A, Fulco AJ, Cheesman MR, von Wachenfeldt C, Munro AW (2004) Expression, purification, and characterization of Bacillus subtilis cytochromes P450 CYP102A2 and CYP102A3: flavocytochrome homologues of P450 BM3 from Bacillus megaterium. Biochemistry 43:5474-5487

109. Chowdhary PK, Alemseghed M, Haines DC (2007) Cloning, expression and characterization of a fast self-sufficient $\mathrm{P} 450$ : CYP102A5 from Bacillus cereus. Arch Biochem Biophys 468:32-43

110. Chiang C-H, Ramu R, Tu Y-J, Yang C-L, Ng KY, Luo W-I, Chen CH, Lu Y-Y, Liu C-L, Yu SSF (2013) Regioselective hydroxylation of $\mathrm{C} 12-\mathrm{C} 15$ fatty acids with fluorinated substituents by cytochrome P450 BM3. Chem Eur J 19:13680-13691 
111. Dubey KD, Wang B, Shaik S (2016) Molecular dynamics and QM/MM calculations predict the substrate-induced gating of cytochrome P450 BM3 and the regio- and stereoselectivity of fatty acid hydroxylation. J Am Chem Soc 138:837-845

112. Oliver CF, Modi S, Sutcliffe MJ, Primrose WU, Lian L-Y, Roberts GCK (1997) A single mutation in cytochrome P450 BM3 changes substrate orientation in a catalytic intermediate and the regiospecificity of hydroxylation. Biochemistry 36:1567-1572

113. Glieder A, Farinas ET, Arnold FH (2002) Laboratory evolution of a soluble, self-sufficient, highly active alkane hydroxylase. Nat Biotechnol 20:1135-1139

114. Ost TWB, Miles CS, Murdoch J, Cheung YF, Reid GA, Chapman SK, Munro AW (2000) Rational re-design of the substrate binding site of flavocytochrome P450 BM3. FEBS Lett 486:173-177

115. Li QS, Schwaneberg U, Fischer M, Schmitt J, Pleiss J, Lutz-Wahl S, Schmid RD (2001) Rational evolution of a medium chainspecific cytochrome P-450 BM-3 variant. Biochim Biophys Acta Protein Struct Mol Enzymol 1545:114-121

116. Li Q-S, Ogawa J, Shimizu S (2001) Critical role of the residue size at position 87 in $\mathrm{H}_{2} \mathrm{O}_{2}$-dependent substrate hydroxylation activity and $\mathrm{H}_{2} \mathrm{O}_{2}$ inactivation of cytochrome P450BM-3. Biochem Biophys Res Commun 280:1258-1261

117. Bernhardt R, Urlacher VB (2014) Cytochromes P450 as promising catalysts for biotechnological application: chances and limitations. Appl Microbiol Biotechnol 98:6185-6203

118. Schneider S, Wubbolts MG, Oesterhelt G, Sanglard D, Witholt B (1999) Controlled regioselectivity of fatty acid oxidation by whole cells producing cytochrome P450BM-3 monooxygenase under varied dissolved oxygen concentrations. Biotechnol Bioeng 64:333-341

119. Kühnel K, Maurer SC, Galeyeva Y, Frey W, Laschat S, Urlacher VB (2007) Hydroxylation of dodecanoic acid and (2R,4R,6R,8R)-tetramethyldecanol on a preparative scale using an NADH-dependent CYP102A1 mutant. Adv Synth Catal 349:1451-1461

120. Cryle MJ, De Voss JJ (2004) Carbon-carbon bond cleavage by cytochrome P450(BioI)(CYP107H1). Chem Commun 7:86-87

121. Kitazume T, Tanaka A, Takaya N, Nakamura A, Matsuyama S, Suzuki T, Shoun H (2002) Kinetic analysis of hydroxylation of saturated fatty acids by recombinant P450foxy produced by an Escherichia coli expression system. Eur J Biochem 269:2075-2082

122. Lentz O, Li QS, Schwaneberg U, Lutz-Wahl S, Fischer P, Schmid RD (2001) Modification of the fatty acid specificity of cytochrome P450 BM-3 from Bacillus megaterium by directed evolution: a validated assay. J Mol Catal B 15:123-133

123. Bruhlmann F, Fourage L, Ullmann C, Haefliger OP, Jeckelmann N, Dubois C, Wahler D (2014) Engineering cytochrome P450 $\mathrm{BM} 3$ of Bacillus megaterium for terminal oxidation of palmitic acid. J Biotechnol 184:17-26

124. Honda Malca S, Scheps D, Kuehnel L, Venegas-Venegas E, Seifert A, Nestl BM, Hauer B (2012) Bacterial CYP153A monooxygenases for the synthesis of omega-hydroxylated fatty acids. Chem Commun 48:5115-5117

125. Scheps D, Honda Malca S, Richter SM, Marisch K, Nestl BM, Hauer B (2013) Synthesis of omega-hydroxy dodecanoic acid based on an engineered CYP153A fusion construct. Microb Biotechnol 6:694-707

126. Kim D, Cryle MJ, De Voss JJ, Ortiz de Montellano PR (2007) Functional expression and characterization of cytochrome P450 52A21 from Candida albicans. Arch Biochem Biophys 464:213-220

127. Hoch U, Zhang Z, Kroetz DL, Ortiz de Montellano PR (2000) Structural determination of the substrate specificities and regioselectivities of the rat and human fatty acid $\omega$-hydroxylases. Arch Biochem Biophys 373:63-71

128. Imaishi H, Ishitobi U (2008) Molecular cloning of CYP76A3, a novel cytochrome P450 from Petunia hybrida catalyzing the $\omega$-hydroxylation of myristic acid. Biol Plant 52:242-250

129. Notonier S, Gricman L, Pleiss J, Hauer B (2016) Semirational protein engineering of CYP153AM.aq.-CPRBM3 for efficient terminal hydroxylation of short- to long-chain fatty acids. ChemBioChem 17:1550-1557

130. Lu W, Ness JE, Xie W, Zhang X, Minshull J, Gross RA (2010) Biosynthesis of monomers for plastics from renewable Oils. J Am Chem Soc 132:15451-15455

131. Tran NH, Nguyen D, Dwaraknath S, Mahadevan S, Chavez G, Nguyen A, Dao T, Mullen S, Nguyen TA, Cheruzel LE (2013) An efficient light-driven P450 BM3 biocatalyst. J Am Chem Soc 135:14484-14487

132. Zachos I, Gaßmeyer SK, Bauer D, Sieber V, Hollmann F, Kourist R (2015) Photobiocatalytic decarboxylation for olefin synthesis. Chem Commun 51:1918-1921

133. Paul CE, Churakova E, Maurits E, Girhard M, Urlacher VB, Hollmann F (2014) In situ formation of $\mathrm{H} 2 \mathrm{O} 2$ for $\mathrm{P} 450$ peroxygenases. Bioorg Med Chem 22:5692-5696 